\title{
Metodología Jurídica
}

\author{
Alfonso Pérez Moreno \\ Catedrático de Derecho Administrativo \\ Universidad de Sevilla
}

\begin{abstract}
SUMARIO: INTRODUCGIÓN.- I. PLANTEAMIENTO DEL PROBLEMA DEL MÉTODO.- A. Ciencia, Filosofia y Derecho.- B. Especialidades de la cuestión metodológica en el Derecho Administrativo.- C. Clases de métodos y su aplicación en el Derecho Administrativo.- II. POSICIONES METODOLÓGICAS Y SUS MANIFESTACIONES EN EL DERECHO ADMINISTRATIVO.- A. El método exegético como expresión de la carencia de ciencia jurídica.- B. El método histórico: negación de la estatalidad del Derecho y afirmación de la costumbre. C. El método lógico-jurídico y la construcción del Derecho Administrativo. Los excesos del formalismo y su revisión. Doctrina española.- D. La jurisprudencia de los intereses como primado de la experiencia vital.E. El sociologismo jurídico y la sociología como dato auxiliar para la construcción del Derecho Administrativo.- F. Modernas tendencias metodológicas (referencias al estructuralismo y al renacimiento del pensamiento tópico).- a) Consideraciones generales.- b) Referencia al estructuralismo jurídico.- c) Peculiaridad del razonamiento jurídico: la tesis de VIEHWEG sobre el pensamiento tópico. La posición de GARCÍA DE ENTERRÍA.- III. CONCLUSIONES.- IV. EL MÉTODO DE ENSEÑANZA.- A. Pedagogía, investigación y cooperación.- B. Medio y técnicas de enseñanza.- C. Plan de enseñanza.
\end{abstract}

\section{Resumen:}

La metodología jurídica viene atravesando la crisis producida por el impacto de la impresionante producción normativa y su movilidad. El desprestigio de la ley y su vinculación a la coyuntura. El Derecho Administrativo no requiere un método exclusivo, pero sí es un campo de experimentación de la bondad de los métodos aplicables a la ciencia del Derecho. Se analizan las distintas posiciones metodológicas (métodos exegético, histórico, lógico-jurídico, jurisprudencia de intereses, sociologismo jurídico, estructuralismo, pensamiento tópico) llegando a unas conclusiones. Finalmente, se hace una referencia al método de enseñanza.

Abstract: Legal methodology is currently in crisis due to the impact of the incredible amount of legislation and its mobility. The discrediting of the law 
and its relationship with the current situation. Administrative law requires no exclusive method, but it is an experimental field when it comes to the methods applied to the science of law. The various methodological positions are analyzed (exegetic, historic, logical-legal, vested jurisprudence, legal sociologism, structuralism and topical thought methods) to reach conclusions. Finally, reference is made to the teaching method.

Palabras clave: Método jurídico. Posiciones metodológicas. Exégesis. Método lógico-jurídico. Jurisprudencia de intereses. Sociologismo. Estructuralismo. Construcción jurídica. Investigación jurídica. Pedagogía.

Key words: Legal methodology. Methodological positions. Exegesis. Logical-legal method. Vested jurisprudence. Sociologism. Structuralism. Legal construction. Legal research. Pedagogy.

\section{INTRODUCCIÓN}

En los últimos tiempos la metodología jurídica no ha mantenido la posición central en la obra de los estudiosos, quedando incluso olvidada en los trabajos de los jóvenes investigadores pese a constituir muchos de ellos importantes aportaciones. No sólo hay que considerar como causa la desequilibrada relación entre filosofía y técnica -entendiendo comprendido en esta palabra el impresionante cúmulo formado por la producción normativa-, sino también la rapidez y laxitud de las políticas legislativas que reducen a niveles sociológicos o de pura facticidad los motivos de los cambios y transformaciones en los ordenamientos jurídicos.

Estos fenómenos son especialmente sensibles en el Derecho Administrativo, como se expondrá después. Pero de ello no se ha de derivar la idea de que es necesario un método propio de este Derecho.

La influencia de los criterios de valoración en los recientemente inaugurados procedimientos de selección del profesorado ha obligado a retomar la cuestión metodológica. En el curso de la programación de seminarios y conferencias sobre la ciencia, organizado por la Universidad de Jaén en el último trimestre de 2008, tuve el honor de exponer unas clásicas reflexiones sobre metodología jurídica que se sintetizan en este trabajo. 


\section{PLANTEAMIENTO DEL PROBLEMA DEL MÉTODO}

Por vía de introducción, vamos a hacer unas consideraciones previas que nos pongan en contacto con la aguda problemática del método en las ciencias jurídicas en general y en el Derecho administrativo en particular y que nos sitúen ante algunas nociones básicas para discernir, definir y entender -conforme señaló ZUBIRI- ${ }^{1}$ en esta ardua cuestión.

\section{A. CIENCIA, FILOSOFÍA Y DERECHO}

Las interrelaciones entre el conocimiento científico y el conocimiento filosófico del Derecho encuentran su máxima expresión en el tema del método. La teoría del método de una ciencia -ese "ir a lo largo del buen camino", que denota su significado etimológico-, es, como expresa LARENZ "una reflexión sobre su propia actividad"2; y esto origina la necesidad del conocimiento científico mismo sobre el objeto de la ciencia jurídica, en nuestro caso; pero también, el ineludible concurso de la Filosofía del Derecho. Como ha señalado agudamente $\mathrm{CERRONI}^{3}$, parte de la distinción kantiana entre el "quid iuris" y el "quid ius" la necesidad de una distinción entre ciencia jurídica y filosofía del Derecho, "la legitimación teórica de un doble y distinto trabajo sobre el derecho: el trabajo del científico que estudia y sistematiza el derecho positivo, y el trabajo del filósofo que define el concepto mismo de derecho y nos proporciona los criterios últimos de su valoración". La consecuencia de esta escisión ha determinado la perplejidad de la ciencia jurídica sobre su propio objeto; entre todas las ciencias sociales que en el transcurso de siglo y medio se han ido constituyendo al mismo tiempo que proclamaban su emancipación con respecto a la filosofía, la ciencia jurídica es probablemente la única que sigue todavía discutiendo acerca de la naturaleza de su objeto y que, incluso, ha expresado muchas veces la imposibilidad de definirlo. De lo que CERRONI deriva que la ciencia jurídica no ha puesto todavía a pun-

\footnotetext{
1 ZUBIRI, "Naturaleza. Historia. Dios", Madrid, 1944, pág. 81. "El saber humano fue, en un principio, un discernir el ser del parecer; se precisó, más tarde, en definir lo que es; se completó, finalmente, en un entender lo definido. Pero a su vez entender ha podido significar: o bien $\underline{\text { de- }}$

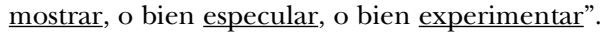

${ }^{2}$ LARENZ, K., "Metodología de la Ciencia del Derecho”, Barcelona, 1966, pág. 7.

3 CERRONI, U., "Metodología e scienza sociale", 1968; traducción española, "Metodología y ciencia social”, Barcelona, 1971; págs. 86 y ss.
} 
to su método ${ }^{4}$. En verdad que existe una tensión entre el conocimiento científico concreto del que ha de extraerse toda la reflexión metódica, y el conocimiento filosófico que cae fuera de la ciencia positiva concreta pero que es necesario para formular la reflexión sobre la construcción jurídica de ésta ${ }^{5}$. En expresión de HERNÁNDEZ GIL, "La metodología -como disciplina del método a seguir en el operar con una materia científica, bien sólo con fines de investigación, bien, además, con fines de aplicación- entraña un autoconocimiento de su cultivador. En la investigación metodológica, la ciencia misma se torna objeto de nuestra reflexión"6.

Tradicionalmente se ha venido, así manteniendo una división tripartita de la investigación sobre el Derecho: investigación lógica o crítica, investigación histórica o fenomenológica e investigación deontológica o valorativa ${ }^{7}$. La integración de las tres subraya, sin embargo, la dependencia de la filosofía, porque el método no sólo plantea la temática acerca de unas reglas determinadas de carácter lógico que nos conduzcan a la verdad, sino también, el de la posibilidad de conocimiento de esa verdad, los límites y naturaleza de la misma. De aquí que la metodología en general, y la metodología jurídica en particular -en la que quizás con un exceso de simplismo no se constata más que una reproducción de la problemática de aquella- esté profundamente influida por las mutaciones de las concepciones filosóficas, aunque cuando la recepción de éstas se producen en el ámbito jurídico puede que ya aquellas hayan cambiado. De lo expuesto puede extraerse una inmediata consecuencia: la necesidad de atenerse a la realidad concreta del Derecho, de sus propias técnicas, de su "modus operandi", como centro de todas las reflexiones metódicas; porque, como no han podido por menos de destacar quienes han afrontado el problema desde esa fructífera perspectiva, "desde su origen, la ciencia

\footnotetext{
${ }^{4}$ CERRONI, U., "Ibidem”, pág. 105.

${ }^{5}$ GARCÍA DE ENTERRÍA, "Reflexiones sobre la Ley y los principios generales del Derecho en el Derecho Administrativo”, R.A.P. núm. 40; según indica, procede este trabajo de su Memoria Pedagógica, págs. 189 y 190.

${ }^{6}$ HERnÁNDEZ GIL, A., "Metodología de la Ciencia del Derecho", Madrid, 1971; que es la reimpresión de su "Metodología del Derecho", pág. 18 de este Tomo I; pues la obra ha pasado a tener tres tomos.

${ }^{7}$ CERRONI, U., ob. cit., pág. 122.
} 
del derecho -en expresión de ENGISCH $^{8}$ - es una ciencia práctica. Los romanos, a quienes les corresponde el imperecedero mérito de haber fundado esta ciencia, sabían perfectamente lo que ella significaba. La celebraron como la "divinarum adque humanarum rerum notitia"; la consideraron, por tanto, como la más viviente de todas las ciencias, y gracias a su derecho y a su ciencia del derecho se transformaron en un pueblo grande y poderoso".

Ese punto media en que se sitúa el Derecho entre lo metafísico y lo técnico, es un peculiar dato para su introspección. Partiendo de la distinción de DILTHEY entre ciencias de los sistemas de cultura y ciencias de la organización externa de la sociedad, afirma, GARCÍA TREVIJANO que "a través del Derecho es precisamente por donde se unifican, o al menos llegan a tener un contacto, los sistemas de cultura con los externos" $"$.

\section{B. ESPECIALIDADES DE LA GUESTIÓN METODOLÓGICA EN EL DERE- CHO ADMINISTRATIVO}

No creemos en la existencia de un método propio del Derecho Administrativo distinto del que corresponda a las demás ramas jurídicas. La unidad sustancial del Derecho se impone aquí, como en otros muchos aspectos, sobre las pretensiones cantonales ("taifistas") de los especialistas en ramas concretas. A esa mima negación de exclusividad metódica en nuestra disciplina llega GONZÁLEZ PÉREZ, después de analizar algunas tesis disidentes (BERTHELEMY Y LATOURNERIE) ${ }^{10}$. Es innegable el efecto especificador de las características propias del Derecho Administrativo: su complejidad, su extraordinaria movilidad; la crónica imposibilidad codificadora total, la continua promulgación de normas promulgación de normas por la inmediación de la Administración a la sociedad, por la disponibilidad de poderes normativos propios, por su obligada respuesta a las situaciones que, en todos los campos, se

\footnotetext{
${ }^{8}$ ENGISCH, K., "Einführung in das juristische denken", Stuttgart, 1956; traducción española, "Introducción al pensamiento jurídico", Madrid, 1967, págs. 16 y 17.

${ }^{9}$ GARCÍA TREVIJANO FOS, “Tratado...”, ob. cit., pág. 167 del Tomo I.

${ }^{10}$ GONZÁLEZ PÉREZ, J., "El método en el Derecho Administrativo”, R.A.P. núm. 22, págs. 27 a 31. LATOURNERIE, "Essai sur les methodes jurisdictionnelles du Conseil d'Etat", en libro jubilar del 150 aniversario del Conseil d'Etat, 1952.
} 
presentan, muchas veces con urgencia, en la vida social ${ }^{11}$. Pero de todo ello no se ha de derivar un tratamiento metódico exclusivo para este Derecho; sino su consideración como excepcional campo de experimentación de la bondad de los métodos aplicables a la ciencia del Derecho. En efecto, sustancialmente y por la experiencia histórica, esto es lo más destacable de la cuestión metodológica en el Derecho Administrativo. Junto a esa enorme producción de normas a todos los niveles, y su extraordinaria movilidad (normas coyunturales, leyes-medida, etc.), destaca la importancia del elemento teleológico: la finalidad es aquí un fuerte polo de atracción, instrumentaliza todo el esquema abierto que es el ordenamiento jurídico-administrativo. No funciona éste con la pretensión de inscribir la finalidad en un sistema cerrado, mediante la codificación -que es el caso del Derecho privado-, y limitar la tarea a la exégesis o a la deducción de los conceptos formales del sistema; su función es la de realización de la justicia mediante un esquema normativo abierto. En el fondo, la codificación devino, en buena parte, también esquema normativo abierto, cuando se constata que la vida supera las herméticas previsiones del legislador; de aquí la importancia que para el Derecho privado tuvo la experiencia que estaba viviendo el Derecho Administrativo, especialmente en Francia, como se demostró -según destaca GARRIDO FALLA- en la clásica obra de GENY, influida más que influyente, por el método de la jurisprudencia contencioso-administrativa del Consejo de Estado ${ }^{12}$.

Queda, pues, demostrado sustancial e históricamente, esa especial aptitud del Derecho Administrativo para comprobar la validez de los métodos; si no por esas sus especialidades tiene un método distinto de las demás ciencias jurídicas, sí es un excepcional laboratorio para analizar el valor de los métodos y ofrecer, así, a éstas el importante servicio de señalarles el método jurídico más adecuado.

\section{CLASES DE MÉTODOS Y SU APLICACIÓN EN EL DERECHO ADMI- NISTRATIVO}

En función de distintos criterios orientadores es posible realizar diversas clasificaciones de los métodos. A los efectos de este trabajo, nos interesa des-

${ }^{11}$ GARCÍA DE ENTERRÍA, "Reflexiones sobre la Ley...”, cit., pág. 203.

12 GARRIDO FALLA, "Las transformaciones del régimen Administrativo", $1^{a}$ edición, 1954, pág. 75. Las obras de François GENY, "Méthode d'interpretation et sources en Droit privé positif", París, 1899 y "Science et technique en Droit privé positif", París, 1914-24. Y de su hijo Bernard BENY, "De la méthode et la technique du Droit privé positif a celles du Droit Administratif", en el libro jubilar del Consejo de Estado, cit. En nota 10. 
tacar la distinción por la forma del razonamiento, y la que atiende al objeto de la actividad. Por la forma o itinerario del razonamiento se contraponen el método inductivo y el deductivo, analítico y sintético. El método inductivo implica un estrecho contacto con la realidad, y en el caso de las ciencias jurídicas, determina una observación de la realidad social, de los casos concretos para poder elevarse a la formulación de una norma general. El método deductivo va de lo general a lo particular, y, separado de la observación de la realidad social a la que se quiere conformar con ideas previas, puede determinar una falta grave de efectividad, y, a la larga, la indigencia social del Derecho. GARCÍA TREVIJANO contesta a la pregunta de qué método debe ser escogido para una rama jurídica en los siguientes términos: "El método inductivo tiene una primera fase, de ir induciendo a través de casos una serie de datos o de momentos que hagan posible la creación de una norma de tipo general. Una vez formada la norma de tipo general, entonces utilizaremos el método deductivo"13. Para GONZÁLEZ PÉREZ “el jurista debe utilizar: el Método deductivo, infiriendo criterios de adecuación de los principios generales de justicia (Derecho natural) y de los de la política (idea de la vida a realizar en un pueblo y en un tiempo determinado; el método inductivo, conociendo la realidad social (estructura social, política y económica real) y la realidad jurídica (eficacia real de las normas en la vida social) para que sirva de base para la ecuación jurídica (realización práctica en la materia jurídica)"14.

Ciertamente, la inducción es necesaria, y en el Derecho Administrativo debe operar sobre la llamada parte especial, de tal forma que toda la construcción de la parte general, que con tanto rigor científico ha permitido redimir a ésta disciplina de sus primitivas manifestaciones asistemáticas, no tendría validez alguna si no está profundamente vitalizada con la afluencia de datos y principios extraídos de la parte especial ${ }^{15}$. A nuestro juicio este es el momento en que puede ser relevante también la ciencia de la Administración, ya que no sólo el Derecho positivo (y en esto diferimos de GARCÍA TREVIJANO), sino la realidad social concreta de base, ha de ser tenida en cuenta para inducir los conceptos, principios y categorías de la parte general.

Si nos detenemos ahora en la distinción de métodos en función del objeto de la actividad, en lo que a las ciencias jurídicas interesa, se discrimina en-

\footnotetext{
${ }^{13}$ GARCÍA TREVIJANO, ob. cit., pág. 173.

14 GONZÁLEZ PÉREZ, “El método...”, cit., pág. 32.

${ }^{15}$ GARCÍA TREVIJANO, Ibídem, pág. 174.
} 
tre métodos de conocimiento, de elaboración, de aplicación y de enseñanza. Existe una gran diferencia entre éste último y aquéllos, como situados en diversos planos; en cambio, sólo algunos matices pueden encontrarse en el método de aplicación que lo separen de los dos primeros. Todas las referencias que venimos, y continuaremos, haciendo a la cuestión metodológica no tienen en cuenta el método de enseñanza, al que dedicaremos especial atención al final de ésta parte de la Memoria. Distintas de estas clasificaciones basadas en aspectos técnicos, son las corrientes o concepciones metodológicas, que, como trasunto de las ideas filosóficas, se han ido produciendo a lo largo de la historia. Desde esta perspectiva, se contempla el Derecho Administrativo inmerso en un conjunto de conocimientos históricos, económicos, políticos, técnicos; la red conceptualista de los positivismos; o vivificado por los principios de justicia material (Derecho natural). Vamos, pues, a considerar las posiciones metodológicas y su repercusión en el Derecho Administrativo.

\section{POSICIONES METODOLÓGICAS Y SUS MANIFESTACIONES EN EL DERECHO ADMINISTRATIVO}

Sin pretender agotar, ni con mucho, todas las posiciones metodológicas que han tenido, o tienen, una resonancia en el campo de la ciencia jurídica, vamos a destacar tan sólo aquéllas que han tenido una mayor influencia en el Derecho Administrativo, sin perjuicio de plantearnos una interrogante sobre el posible papel de otras más recientes tendencias, concretamente el estructuralismo. Así, sucesivamente, consideraremos a continuación, los métodos exegético, histórico, positivista y formalista; jurisprudencia de intereses, sociologismo jurídico; y, entre las modernas tendencias: referencias al estructuralismo, y pensamiento tópico.

\section{A. EL MÉTODO EXEGÉTICO COMO EXPRESIÓN DE LA CARENCIA DE CIENCIA JURÍDICA}

Con razón se ha imputado al método exegético ser causa "de la leyenda negra del Derecho Administrativo como disciplina farragosa e inabordable" 16 . Basta recordar las especialidades antes expuestas -falta de codificación, esquema normativo abierto, movilidad, contingencia, etc.- para comprender los

${ }^{16}$ GARCÍA OVIEDO-MARTÍNEZ USEROS, "Derecho Administrativo”, 9ª edic., I, pág. 94. 
funestos efectos que podían derivarse de una mera descripción del contenido de las disposiciones, sin engarzarlas en un sistema de principios y conceptos generales. Más que obras científicas, los escritos de éste carácter son o diccionarios o guías -como el Tratado de DUFOUR que estudiaba las materias por orden alfabético-. La escuela exegética, como portadora de ésta metodología en los estudios jurídicos, se localiza en Francia, a raíz de la promulgación del Código Napoleón, desarrollándose a lo largo del siglo XIX, aunque en franca decadencia en las postrimerías de éste, recibiendo el golpe de gracia de la antes referida obra de François GENY. Pese a la completa biografía de dicha escuela, no puede desconocerse la existencia de otras manifestaciones importantes de la exégesis en el campo del Derecho: HERNÁNDEZ GIL destaca como precedentes los glosadores y comentaristas ${ }^{17}$. Creemos, sin embargo, que es muy importante subrayar las distintas motivaciones y planteamientos de la exégesis en cada caso; de mucho más intención política en la escuela francesa posterior a ese logro de la burguesía que fue el Code. En ambos casos existe, sin embargo, una nota común: la falta de un auténtico conocimiento científico, el no haber superado el plano del saber vulgar. La base de todo es la ley; fuera de ella es inútil indagar el concepto de Derecho. Existe una supervaloración del Código y de la ley misma; LAURENTE resumirá el pensamiento con estas frases: "Los Códigos no dejan nada al arbitrio del intérprete; la misión de éste no es elaborar el Derecho, el Derecho está elaborado"18. Se aprecia aquí un radical positivismo, y en este sentido puede enlazarse la exégesis con el método de la jurisprudencia de conceptos ${ }^{19}$.

En seis notas resume HERNÁNDEZ GIL los rasgos metodológicos de la Escuela que consideramos:

1) "El derecho positivo lo es todo y todo el derecho positivo está constituido por la ley"; se rechaza, pues, toda consideración sociológica, espiritual, moral o económica.

2) "Interpretación dirigida a buscar la intención del legislador". La búsqueda de la "voluntas legislatoris" consumando la exégesis de la ley,

${ }^{17}$ HERNÁNDEZ GIL, "Metodología de la Ciencia del Derecho”, cit. Pág. 74 y ss.

${ }^{18}$ LAURENT, "Cours élémentaire de Droit civil”, pág. 9, del tomo I.

${ }^{19}$ HERNÁNDEZ GIL, ob. cit., pág. 85. "Les es común -dice- en efecto, el exagerado normativismo, su culto a la lógica, su afán por la generalización, su creencia en las abstracciones y en cuanto implique un apartamiento de la vida real". 
bastaría si el Derecho sólo fuese un sistema de mandatos del Estado. Pero, como señala GARCÍA DE ENTERRÍA después de hacer esa constatación, existe una "voluntas legis", y "la autonomía de esa supuesta voluntad de la ley respecto de su autor y el hecho de su movilidad en el tiempo no podrían explicarse si la ley misma no fuese vista como expresión de algo sustancial y más profundo" 20 , con lo que apunta a los principios generales del Derecho.

3) "Descubierta esa intención y establecido el principio fundamental que consagra, es preciso obtener todas las consecuencias, dar a la norma la extensión de que sea susceptible, sirviéndose de un proceso deductivo". Recordamos aquí la antes denunciada separación de la realidad que el método deductivo único origina.

4) "Se niega valor a la costumbre; las insuficiencias de la ley se salvan a través de la ley misma, mediante la analogía”. Como expresa GARCíA DE ENTERRÍA, esta idea de expansión lógica de las normas singulares, es "la primera ficción que se requiere para poder dejar en pie la concepción básica de la estatalización total del Derecho", hoy insostenible ${ }^{21}$.

5) "Se tienen muy en cuenta los argumentos de autoridad, con el consiguiente respecto a las obras de los antecesores".

6) "Y, en suma, se atribuye al derecho un carácter eminentemente estatal"22.

De todas las objeciones formuladas por GENY contra el método exegético, la mas atendible en Derecho Administrativo es la profunda inmovilización que dicho método produce, lo que produce un vivo divorcio entre ley realidad social. Hemos señalado la existencia de normas coyunturales, de disposiciones contingentes, que, una vez superadas las circunstancias que las determinaron se extinguen, cesan en su vigencia (o, si formalmente no ocurre así, entran en un "sótano de trastos viejos", peculiar manifestación del desuso en el Derecho Administrativo, cuyo estudio, que se prevé apasionante, esta por hacer); pero no puede olvidarse que no todas las leyes administrativas son tan episódicas, que cumplen muchas de ellas su vocación de permanencia, y acreditan, a veces, una longevidad más que centenaria, pese a su inmediatividad con la viva realidad (por ej. Ley de Aguas, de 1879).

\footnotetext{
${ }^{20}$ GARCÍA DE ENTERRÍA, “Reflexiones sobre la ley...”, cit., pág. 192.

${ }^{21}$ GARCÍA DE ENTERRÍA, Ibidem, pág. 191.

${ }^{22}$ HERNÁNDEZ GIL, ob. cit., págs. 81 a 83.
} 
La profunda congelación que, en tales materias y leyes, produce un método exegético, es obvia; y es asimismo explicable, que, en tales circunstancias, aflores los subjetivismos y la norma escrita se convierta en la cobertura de las más contradictorias explicaciones de su contenido. Estas consideraciones, y las que descubren los obstáculos de dicho método para la construcción científica del Derecho Administrativo, se encuentran destacadas en los administrativistas europeos que toman conciencia e inician la recepción del método jurídico; revisando y criticando el camino de la exégesis seguido, por lo general, por los primitivos cultivadores de estos estudios. Así, ORLANDO, separaba el Derecho y la ley, los principios jurídicos y los comentarios a la legislación positiva, en definitiva, la auténtica ciencia del Derecho y el conocimiento de la ley en cada momento vigente; aspectos que confunde el método exegético ${ }^{23}$. Y, entre nosotros, GASCÓ Y MARÍN, señaló: "Sería absurdo reducir todo al método exegético. Por haberlo abandonado como elemento único, han podido los tratadistas alemanes y franceses, como lo han hecho los italianos y lo están haciendo los españoles, ir formando esas construcciones jurídicas que aparentemente han salido de la nada, y que en realidad han ido surgiendo de la consideración de que hay algo más que reglas aisladas, que es preciso explicar o interpretar aisladamente o en relación puramente parcial, de pensar que la vida de los Estados, su actuación, tiene que obedecer a principios fundamentales, que la vida jurídica los necesita también y que esas reglas generales hay que ir derivándolas, no sólo mediante la inducción, sino utilizando también la deducción" ${ }^{24}$.

La etapa inicial del Derecho administrativo en todos los países estuvo dominada por el método exegético, incluso en los países hispanoamericanos. Como expresa VILLEGAS BASAVILBASO "La obra de FERREYRA - titulada "Derecho administrativo general y argentino", publicada en 1866- es un ejemplo de ésta tendencia clásica, ya que define ésta disciplina "El conjunto de leyes y decretos que determinan las relaciones de la sociedad con los ciudadanos en el orden administrativo" 25 . Y es que, como indicó CARNELUTTI, "la ciencia

\footnotetext{
${ }^{23}$ ORLANDO, "Principii di Diritto Amministrativo", 1921, págs. 3 y s.; y "Primo Trattato completo di Diritto amministrativo italiano”, vol. I, Milano, pág. 54.

${ }^{24}$ GASCÓN Y MARÍN, “Tratado de Derecho Administrativo”, Tomo I, Madrid, 1931, pág. 134.

25 VILLEGAS BASAVILBASO, "Derecho Administrativo", Buenos Aires, 1949, Tomo I, pág. 426
} 
supera la fase del empirismo para entrar en la del tecnicismo cuando se propone el problema de su propia regla" ${ }^{26}$.

En nuestra actual doctrina, y con preponderante referencia a la aplicación del Derecho Administrativo (ya que para su elaboración se inclina por la jurisprudencia de intereses, con las matizaciones que más adelante examinaremos), defiende el método exegético GARRIDO FALLA ${ }^{27}$.

A su juicio "la exégesis es la única forma lícita de razonar admitida por los Tribunales y en cualquier sector en que se manifiesta la práctica del Derecho"; pero el hecho de que el legislador no defina, en muchos casos, en qué consiste el interés público, hace posible unas peculiaridades de la exégesis en el Derecho Administrativo, en el que la interpretación "ha de hacerse en consonancia con 1) los principios político-jurídicos que informan el Ordenamiento positivo, 2) la noción de interés público, y 3 ) a falta de precepto positivo expreso, los principios del Derecho natural"; todo ello no desvirtúa "la idea radical de la exégesis, a saber: que el intérprete ha de considerarse a sí mismo en una situación de subordinación con respecto a la Ley escrita, o lo que es lo mismo, que el intérprete no es legislador y ha de admitir, por tanto, la Ley, le guste o no le guste". Recuerda, así, la Sentencia del Tribunal Supremo de 20 de febrero de 1965, cuando afirma: “... el Estado dicta el Derecho y a la jurisdicción sólo atañe proyectarlo y aplicarlo al caso concreto; por ello es peligroso usar de un subjetivismo interpretativo que desborde la norma, que infringiría nuestra Ley Orgánica de Tribunales, que les confiere sólo juzgar y hacer ejecutar lo juzgado, pero no una labor legislativa al socaire de una interpretación" ${ }^{28}$. GARRIDO refuerza su pensamiento por la circunstancia de la aparición de modernas leyes de más nivel técnico, en los últimos tiempos; frente a ello GARCÍA DE ENTERRÍA opone que el riesgo de pobreza de una interpretación exegética y literalista (que caracteriza la jurisprudencia tradicional) "es ingenuo creer que no existe cuando lo que se aplican son leyes de alto nivel técnico, que son, quizás más que ningunas, fácilmente resecable por una disposición interpretativa de ese tenor" ${ }^{29}$.

${ }^{26}$ CARNELUTTI, "Metodología del Derecho”, México, 1940, pág. 16

27 GARRIDO FALLA, "La Administración y el método jurídico”, R.A.P. núm. 35,, págs. 45 y ss.; incorporado a su libro "Dos métodos en el estudio de la Administración Pública (Método jurídico y ciencia de la Administración)", Instituto García Oviedo, Sevilla, 1961. Vid. también "Tratado...", cit., págs. 188 y s. del vol. I, donde resume su posición frente a las críticas recibidas.

28 GARRIDO FALLA, “Tratado...”, cit., pág. 189.

${ }^{29}$ GARCÍA DE ENTERRÍA, “Reflexiones sobre la ley...”, cit., pág. 212, nota 88. 


\section{B. EL MÉTODO HISTÓRICO: NEGACIÓN DE LA ESTATALIDAD DEL DE- RECHO Y AFIRMACIÓN DE LA COSTUMBRE}

Ha destacado VERDROS ${ }^{30}$ la evolución de pensamiento que determina el descubrimiento del mundo histórico, que encontraría su expresión en el campo del Derecho, en la llamada Escuela Histórica del Derecho, cuyo máximo representante fue SAVIGNY. En dicha evolución, VICO reaccionó contra el desprecio cartesiano por la historia, y contra los partidarios de la doctrina racionalista del Derecho natural que sólo atendieron al momento histórico en que vivieron; MONTESQUIEU, condicionó el contenido del Derecho al clima, suelo y estilo de vida de los pueblos, realzando el principio de la "naturaleza de las cosas"; HERDER, afirmó que el Derecho no es tan sólo el que disca el Estado, sino el orden jurídico producido por el pueblo en forma natural; y MOSER defendió una doctrina histórica del Estado. Con esas concepciones enlaza la obra de SAVIGNY, en cuyo ensayo "De la vocación de nuestro siglo para la legislación y la ciencia del derecho" (1814), afirmó frente a la propuesta de THIBAUT de sustituir el Derecho vigente por un código nuevo, que "el derecho es ante todo un producto de las costumbres y de las convicciones del pueblo y sólo posteriormente el resultado de la jurisprudencia, de tal manera que es siempre y en todo momento la consecuencia de la acción de fuerzas internas espontáneas y nunca la creación del arbitrio de un legislador"31. Sin detrimento de esa esencial fuente popular del Derecho, existe un esfuerzo científico, de exposición sistemática en forma lógica de conceptos, que corresponde a los jurisconsultos, en virtud -decía SAVIGNY- de la necesaria división de trabajo y puesto que el desarrollo de ese Derecho que antes vivía en la conciencia del pueblo, no permite que su conocimiento sea accesible a todos los miembros de la nación. "Los jurisconsultores -concluía- ejercen sobre el derecho una doble acción: la una, creadora y directa, pues reuniendo en sí toda la actividad intelectual de la nación, desenvuelven el derecho, como representantes de la nación; la otra, puramente científica, pues se apoderan del derecho, cualquiera que sea su origen para recomponerlo y traducirlo en una

30 VERDROS, A., "La filosofía del Derecho del Mundo Occidental. Visión panorámica de sus fundamentos y principales problemas”, Traducción española con adiciones del autor de su obra publicada en 1958; y esta traducción en México, 1962, págs. 239 y ss. Sobre el carácter histórico de las ciencias sociales, vid. KAUFMANN, F., "Metodología de las Ciencias Sociales", México, 1946.

31 SAVIGNY, "De la vocación de nuestro siglo por la legislación y la ciencia del derecho", traducción española. La España moderna, pág. 3. 
forma lógica..." 32 . Estas últimas palabras definen el sentido del elemento "sistemático", que, como ahora comprobaremos, asoció este fundador de la "Revista para la Ciencia Histórica del Derecho" (1815), con el elemento histórico.

En la obra de SAVIGNY descubre LARENZ una evolución desde su etapa de juventud a la de madurez. A juicio del Catedrático de Munich ${ }^{33}$ el resumen de la misma debe destacar los siguientes puntos:

Combinación del método "histórico" y del "sistemático"; el primero, contempla el nacimiento de cada ley dentro de una determinada situación histórica; el segundo, pretende concebir la totalidad de las normas jurídicas y los institutos jurídicos en que se basan como un todo conexo.

Tránsito de la concepción del sistema jurídico sólo como sistema de reglas jurídicas unidas entre sí por una vinculación lógica, en la que las especiales son resultantes de las generales (etapa de juventud); a una concepción de madurez en la que se basa en la conexión orgánica de los institutos jurídicos vivos en la conciencia general: "las reglas jurídicas individuales son inferidas sólo posteriormente, mediante una "abstracción", de los institutos" (etapa de madurez).

Tránsito de una defensa de la vinculación a la letra de la ley (etapa de juventud), a una inclinación "por una más intensa consideración del fin de la ley y de la conexión de sentido que viene dada en la contemplación total del instituto" (etapa de madurez).

Lo que más ha influido de la obra de SAVIGNY ha sido la concepción histórica, y su sentido de sistema científico como conjunto de conceptos jurídicos. En expresión de HERNÁNDEZ GIL, los postulados generales de éste método histórico son: " $1{ }^{\circ}$. Empirismo: el derecho se presenta como algo externo, real, dado, objetivo; su conocimiento se deriva de la experiencia...; $2^{\circ}$. Causalidad y determinismo: todo fenómeno tiene una causa (y así el Derecho); $3^{\circ}$. Irracionalismo y relativismo: El derecho es un cuerpo orgánico, natural. Así surge y vive, en constante producirse, hacerse y rehacerse; sometido, pues, a mutaciones que nada respetan"34.

\footnotetext{
${ }^{32}$ SAVIGNY, "Sistema del Derecho romano actual”, traduc. Española de Messia y Poley, I, págs. 47 y s.

33 LARENZ, “Metodología de la Ciencia del Derecho”, cit. Pág. 32.

34 HERNÁNDEZ GIL, "Metodología...”, cit., pág. 95.
} 
La influencia de SAVIGNY en las elaboraciones posteriores es notable, principalmente en la construcción de la "jurisprudencia de conceptos". La investigación jurídica se somete a partir de él, a unas reglas determinadas: en presencia de una institución jurídica, se busca su origen y se traza la evolución, criticando las fuentes y separando el elemento romano y el germánico; se exponen y critican las opiniones doctrinales; se llega a un concepto definitivo; después se entronca con un todo orgánico, buscando su naturaleza jurídica, mediante su identificación con categoría jurídica típica; finalmente, se la contempla desde perspectiva dinámica, estudiando, nacimiento, adquisición, modificación, pérdida y extinción de derechos y deberes.

Si nos detenemos ahora a considerar la influencia de esta escuela en el Derecho Administrativo, la primera consecuencia es afirmar la imposibilidad de basar exclusivamente en ella su construcción. La ciencia del Derecho Administrativo, sin embargo, ha saltado de un método exegético originario a un método lógico-jurídico, sin haber atravesado entremedio una fase de elaboración histórica. Parecía tan próxima su fecha de nacimiento, tan original su naturaleza y figura, y tan apegada a la concreta realidad del Derecho de cada Estado; que no paró mientes en la importancia de buscar sus raíces más allá incluso del período histórico antecedente al que radicalmente se enfrentaba. No tuvo, pues, auge el método histórico. Y, por otra parte, tampoco lo tuvo el elemento consuetudinario: la aspiración a un sistema de normas escritas en el que se predetermina la vida de la Administración ha dado poco margen a la costumbre, o al menos ha cerrado el paso a una consideración del verdadero valor atribuíble a la costumbre en el Derecho Administrativo.

Tanto en uno como en otro elemento -método histórico y costumbre-, asistimos hoy a una importante evolución, para aguda en cuanto al primero, que en cuanto a la segunda. La recepción del método histórico en nuestra ciencia jurídico-administrativa está produciendo insospechados frutos. En poco menos de treinta años, que han transcurrido desde que nuestros administrativistas iniciaran el interés por volverse hacia la historia, hemos podido conocer las primeras aportaciones a nuestra ciencia en los siglos XVIII y XIX, la existencia de instituciones y perfiles propios de nuestro Derecho Administrativo (como la significación del fomento): el origen de la jurisdicción contencioso-administrativa y su problemática; las primeras experiencias de empresas públicas; las profundas raíces de muchas técnicas jurídicas actuales y de instituciones que parecían no tener historia; y que, desde esta nueva perspectiva han adquirido sentido, fijeza y pureza, al quedar despegadas del concreto entorno para manifestarse en su completo sentido técnico-jurídico. 
No puede decirse otro tanto sobre el estudio de la costumbre, que sigue considerada como fuente de escasa relevancia en el Derecho Administrativo. A nuestro juicio, es muy importante volver sobre este tema en nuestros días, sobre todo por lo que se refiere a la "consuetudo Abrogatoria" 35 , y la elaboración de un concepto de desuso, y su control, que presenta características singulares en nuestra disciplina, supuesto que muchas disposiciones quedan sin cumplir, "extinguidas" por su sentido coyuntural, y no derogadas expresamente, eludidas, etc. No es, sin embargo, este es el lugar para realizar dicho estudio.

\section{EL MÉTODO LÓGICO-JURÍDICO Y LA CONSTRUCGIÓN DEL DERE- CHO ADMINISTRATIVO. LOS EXCESOS DEL FORMALISMO Y SU REVI- SIÓN. DOGTRINA ESPAÑOLA}

La importancia de la "jurisprudencia de los conceptos" como conjunto de direcciones metodológicas llevadas por IHERING y WINDSCHEID a su máxima expresión, es muy destacada en el Derecho Administrativo porque, precisamente, sus planteamientos sirvieron par la construcción jurídica del mismo. Podemos decir que esa metodología lógico-jurídica sirvió de férula para sostener un primer esqueleto de ciencia jurídica administrativa. Se trata de una aplicación de la lógica formal para, por vía de abstracción, componer un sistema de conceptos en base todo ello del Derecho positivo, y sin consideración de elementos extrajurídicos (políticos, económicos, etc.). El positivismo es, pues, la base de toda la doctrina. El origen del método del pensamiento formal-conceptual (como "pirámide de conceptos") en la ciencia jurídica, lo encuentra LARENZ en la obra de PUCHTA, que en este punto se aparta de SAVIGNY. "La tarea de la ciencia -según PUCHTA" 36 - es la de llegar a conocer las proposiciones jurídicas en su conexión sistemática -como condicionándose mutuamente y procediendo cada una de la otra-, a fin de poder elevarse desde las proposiciones hasta su principio y de poder descender también desde los principios hasta sus peldaños más inferiores”.

La figura de IHERING destaca en la elaboración de esta metodología, que, en su primera fase, él mismo calificó de "método histórico-natural"; pero después se convirtió en agudo crítico de la jurisprudencia de los conceptos,

\footnotetext{
${ }^{35}$ FORSTHOFF, "Tratado...", cit., pág. 213, donde critica a MAYER.

${ }^{36}$ LARENZ, “Metodología...”, cit., pág. 35.
} 
evolucionando hacia una posición pragmática, en la que realza el fin, y que va a ser la base de la "jurisprudencia de intereses", es decir, la reacción contra la "Begriffjurisprudenz". Interesa, sin embargo, pese a su apostasía, conocer en sus líneas maestras el pensamiento del autor en aquélla su primera etapa.

Comparaba IHERING la tarea de la construcción jurídica en la elaboración de los conceptos y de los "cuerpos jurídicos", con el esfuerzo de análisis y abstracción seguido para el descubrimiento del alfabeto, y con la química. El proceso lógico de dicha tarea de la técnica jurídica requiere, a su juicio ${ }^{37}$ una "simplificación cuantitativa" y una "simplificación cualitativa", selección de materiales y construcción, análisis, concentración y construcción. La simplificación cuantitativa requiere, pues, operaciones lógicas de análisis de la materia y concentración lógica (hallazgo de principios y fórmulas que compendien los datos singulares); y como técnicas auxiliares de esas dos fundamentales, el conseguir un orden sistemático de la materia (mediante clasificación de los materiales), aplicar una adecuada terminología jurídica (porque las verdades sin expresión técnica son como las monedas que no han recibido el cuño: ni una ni otras entran en circulación), y emplear hábilmente lo que existe (economía jurídica). La simplificación cualitativa supone la construcción jurídica, que se consigue previa una labor de interpretación, y desemboca en un sistema, siguiendo tres leyes: "la construcción doctrinal debe aplicarse exactamente al derecho positivo", "falta de contradicción o unidad sistemática", "la ley de la belleza jurídica": "La construcción es más sencilla cuanto es más perfecta; es decir, más clara, transparente y natural; porque la extrema sencillez en este punto es la manifestación suprema del arte... La construcción es clara cuando hace la relación de que se trata fácil y accesible a nuestra inteligencia; es transparente si el asunto que entraña aparece con claridad en todas sus consecuencias, como la noción de la persona jurídica; y es natural cuando la construcción no pretende derogar ni destruir los fenómenos del mundo físico o intelectual". En la crítica de IHERING destaca LARENZ las inconsistencias derivadas del "lenguaje pseudocientífico conatural" aplicado a los "cuerpos jurídicos", porque "en realidad los conceptos jurídicos elementales no "existen" del mismo modo que "existen" ("teniendo validez") las normas jurídicas, sino que sólo tienen -junto con todas las proposiciones que se consigan en base a ellos mediante deducciones- un valor declarativo teórico; éste se puede valorar todo lo alto que se quiera, pero de ahí no se deduce nada para una validez de estas proposiciones como normas preceptivas" 38 .

\footnotetext{
${ }^{37}$ HERNÁNDEZ GIL, “Metodología...”, cit., pág. 134.

${ }^{38}$ LARENZ, ob. cit., pág. 42.
} 
La jurisprudencia de los conceptos encontró su formulación más acabada en WINDSCHEID. Para él los conceptos jurídicos tienen un cometido práctico y científico, se utilizan para la aplicación del derecho y para la elaboración del sistema; unos tienen por objeto los presupuestos de hecho de los derechos; otros, los derechos mismos o algunas de sus notas o características ${ }^{39}$. Es muy interesante la apreciación de LARENZ que, al denunciar la falta de reflejo de la sustancia espiritual de los institutos jurídicos y del Derecho general a que conduce el pensamiento abstracto-conceptual, advierte: "Sólo porque esta substancia, tácitamente, sigue siendo presupuesta por WINDSCHEID en gran medida -es decir, sólo porque, en realidad, él mismo y el lector vinculan con sus conceptos (como derecho subjetivo y sujeto del Derecho) algo más de lo que la definición dice- se adapta la materia al sistema, sólo por ello salen bien, por lo menos aparentemente, las cuencas" ${ }^{40}$. El fenómeno ha sido destacado entre nosotros por DE CASTRO y lo verifica en la obra de OTTO MAYER, GARCÍA DE ENTERRÍA ${ }^{41}$. Según el ilustre civilista, "si los dislates cometidos no son más, se debe al gran sentido práctico de los mejores juristas, que instintivamente fueron infieles a sus postulados y a seguir, sin confesarlo, los criterios que aconsejaban los principios morales, políticos o sociales" ${ }^{42}$.

Bajo la influencia de esta metodología se inició la construcción jurídica del Derecho Administrativo, la "recepción del método jurídico" en nuestra disciplina $^{43}$. La insuficiente contribución de la exégesis, de una parte; y la mezcolanza de materias y métodos que significaba la ciencia de la Administración, continuadora de la ciencia de la policía; hacía del Derecho Administrativo uno de los campos más fértiles para que germinara el método lógico-jurídico, que venía ya avalado en sus primeras aplicaciones al Derecho público, por ALBRECHT y GERBER, y, muy decisivamente, por LABAND ${ }^{44}$ y JE-

${ }^{39}$ HERNÁNDEZ GIL, ob. cit., pág. 159.

${ }^{40}$ LARENZ, ob. cit., pág. 46.

${ }^{41}$ GARCÍA DE ENTERRÍA, "Reflexiones sobre la ley...”, cit., pág. 206, nota 66.

42 DE CASTRO, "Derecho Civil de España”, ob. cit., pág. 500.

${ }^{43}$ GARRIDO FALLA, "Tratado...", cit., sobre la recepción del método jurídico, págs. 175 y ss. del vol. I.

${ }^{44}$ LABAND, "Le droit public de L'Empire Allemand”, T. I, París, 1900. 
LLINEK $^{45}$. Se desarrolla, así, una poderosa y auténtica ciencia jurídico-administrativa en las obras de MAYER, FLEINER, ORLANDO, D'ALESSIO, ROMANO, ZANOBINI, GASCÓN Y MARÍN, ROYO VILLANOVA, GARCÍA OVIEDO, CAETANO, etc. Fácil brota el entusiasmo de los primeros cultivadores por el nuevo camino. LABAND -de quien dirá LARNAUDE ${ }^{46}$ que construyó el Imperio y sus derechos a golpe de razonamientos, argumentos y teorías jurídicas, despreocupado de la historia, la economía, la filosofía y la política-, describía el método jurídico como análisis de las relaciones jurídicas, determinación de su naturaleza jurídica y de los principios generales a que obedecen, y deducción de consecuencias. No menospreciaba los estudios extrajurídicos (históricos, filosóficos y políticos) aún sobre cuestiones de Derecho público; pero consideraba que no eran preocupación del jurista, que debía superar el diletantismo sobre ellas y la mera compulsa de leyes, para adentrarse en el riguroso trabajo sistemático, con empleo de la lógica, analizar las formas jurídicas, reunir los principios generales y las nociones particulares deduciendo de ellos sus consecuencias. "Découvrir les principes géneraux n'est pas toute la tâche qui s'impose; il faut encore développer les conséquences qui découlent des principes découverts et meter en limiére leur concordance avec les institutions réellement en vigueur et les prescriptions positives des lois" ${ }^{47}$.

El magisterio de LABAND determinó el método jurídico del "Derecho Administrativo alemán", de MAYER, en cuyo prefacio lo reconoce: "He ensayado seguir un sistema puramente jurídico, poco más o menos como lo ha hecho Laband para el derecho público del Imperio Alemán”. Por este método ha sido posibles extraer de entre los distintos elementos que antes integraban el Derecho Administrativo, el elemento formal, coordinándose las varias instituciones de esta disciplina, merced al rigor de una técnica jurídica que ha producido la sistematización jurídica de esta ciencia. Por vez primera está basada en las relaciones jurídicas del sistema, sin preocupaciones sociológicas y políticas, y así se afirma la independencia de las instituciones administrativas, desprendiéndose de su tradicional y vetusta adherencia al viejo tronco del Derecho privado ${ }^{48}$. Y en esta misma directriz se destaca en la obra de FLEINER, en

\footnotetext{
45 JELLINEK, “Allgemeine Staatslechre”, traducción española, cit., (1974).

${ }^{46}$ LARNAUDE, "Le Droit publique. Sa conception. Sa méthode", en "Les méthodes juridiques”, París, 1911, y Prólogo al libro de LABAND.

${ }^{47}$ LABAND, "Le droit public...", cit., pág. 3.

48 MAYER, O., "Derecho Administrativo alemán”, tomo I, Buenos Aires, 1949, pág. XXIV.
} 
la que hace un compendiado relato de las distintas etapas metodológicas de la disciplina desde el Estado-policía, y destaca la utilidad de reducir a sencillas fórmulas jurídicas fundamentales las complejas relaciones. "Con la formulación de estas ideas del Derecho -concluía- se logra aquella gran simplificación que pone al juez y al funcionario administrativo en situación de obrar adecuadamente siempre que se presente una relación jurídica nueva acerca de la cual nada diga la ley ${ }^{49}$.

En Italia es ORLANDO quien ya en 1885 denuncia el exceso de filosofía, política e historia, y el defecto de ciencia jurídica, entre los publicistas ${ }^{50}$. A partir de entonces se ha desarrollado el método dogmático, llegando -como denuncia GARRIDO FALLA- a excesos de abstracción y formalismo jurídico, "donde la realidad aparece contemplada desde muy lejanos horizontes" SANTI ROMANO constataba que "si hasta ahora el Derecho Administrativo ha sido estimado como un laberinto intrincado, se debe a que se creyó función del administrativista el estudio, no sólo de los principios de Derecho, sino también de los infinitos casos a que estos se aplican, lo que es imposible e inútil" "52; si bien más adelante considerase la colaboración necesaria de otras ciencias no jurídicas, y propugnara una aplicación del método jurídico en el Derecho público muy diversa a la que se hacía en Derecho privado ${ }^{53}$.

Para ZANOBINI, "el jurista no debe ignorar los elementos esenciales que justifican la formación del derecho y determinan su utilidad práctica. Puede, a veces, servirse de ellos para mejor pesquisar el valor y la importancia de cada institución. Esto debe decirse particularmente con respecto al derecho administrativo, donde la investigación del fin de la ley tiene, como veremos, buena parte en su interpretación y aplicación. Pese a todo ello, es evidente que el

49 FLEINER, F., "Instituciones de Derecho Administrativo", traducción de ÁLVAREZ GENDIN, 1933, pág. 38 .

${ }^{50}$ ORLANDO, "Scritti varii", "I criteri tecnici per la riconstruzione giuridica del Diritto pubblico", págs. 3 y ss. También, RANELLETTI, "Vittorio Emanuele Orlando nel suo pensiero e nella sua opera", Riv. Trim. Di Diritto pubblico", 1954, págs. 281 y ss.

${ }^{51}$ GARRIDO FALLA, “Tratado...”, cit., pág. 182.

${ }^{52}$ SANTI ROMANO, "Principii di Diritto amministrativo italiano", Milano, 1912, págs. 12 y s.

${ }^{53}$ SANTI ROMANO, "Principii di Diritto constituzionale generale”, Milano, 1947, págs. 21 y ss. 
estudioso no debe sustituir por dichos elementos sustanciales a los puramente lógicos, interpretativos y constructivos, con los que se integra el sistema científico de la investigación jurídica”. De aquí, que distinga entre una parte general, inspirada por el criterio constructivo, y una parte especial, informada por el método descriptivo ${ }^{54}$.

En Portugal introduce el método constructivo, lógico formal, CAETANO, basándose en el criterio de la relación jurídica ${ }^{55}$. Y en España, aunque conscientes de la necesidad de reducir sus excesos, se adopta el método contractivo a partir del presente siglo, destacando las obras de ROYA VILLANVA, GASCÓN Y MARÍN, FERNÂNDEZ DE VELASCO, GARCÍA OVIEDO, etc. Este último no excluye unas referencias al contenido social de la problemática fundamental de las instituciones, sobre todo en la consideración de las particulares manifestaciones de la actividad administrativa, aunque preponderantemente utiliza el método jurídico, "pues la consideración jurídica de las instituciones administrativas, el análisis de las relaciones a que dan lugar, la determinación de los principios que informan y rigen la función de administrar, la sistematización lógica de esta trama constituye el fin cardinal del Derecho administrativo" $" 56$.

Estas expresiones, y las advertencias de GASCÓN Y MARÍN contra los excesos de la construcción dogmática, indican la moderación con que fue acogida entre nosotros, a tal punto que GARRIDO FALLA ha denunciado una falta de pureza metodológica ${ }^{57}$.

Pero la expresión máxima de los excesos formalistas, como última consecuencia de esta dirección metodológica, se produce por la obra de KELSEN -cabeza de la escuela vienesa- que iba a ser trasplantada al Derecho Administrativo por MERKL. Muestras hemos ofrecido ya de este pensamiento en otras partes de esta Memoria, e interesa ahora sintetizar su posición metodológica de base. En el cimiento de la concepción kelseniana se encuentra la separación

\footnotetext{
54 ZANOBINI, “Curso...”, cit., págs. 72 y ss.

55 CAETANO, "O problema do metodo no direito administrativo", separada de "O direito", 1948; y "Tratado de Derecho Administrativo”, edición española de LÓPEZ RODO. Vid. prólogo.

56 GARCÍA OVIEDO-MARTÍNEZ USEROS, "Derecho Administrativo", cit., págs. 109 y s.

57 GARRIDO FALLA, "Dos métodos...”, cit., pág. 88.
} 
entre el "ser" y el "deber ser"58. Las ciencias del ser -explica VERDROSS- son las disciplinas causales, que proporcionan una explicación genética de los fenómenos, los que, a su vez, son presentados dentro de una cadena de causas y efectos. A estas disciplinas se oponen las ciencias normativas, cuyo objeto ya no es el ser, sino el deber ser. A este grupo pertenece la ciencia del Derecho.

El "deber ser" no es un valor ético, sino una forma de pensar. Debe, pues, separarse la ciencia del Derecho, como teoría del Derecho positivo, de la ética, de la sociología, de la psicología; para conseguir la "pureza del método". La ciencia del Derecho es normativa porque se basa en el enlace mental de un hecho con una consecuencia jurídica, fenómeno que KELSEN califica de "imputación". La norma, pues, no es más que un juicio hipotético, alejado de todo contenido, como molde donde se vaciarán los concretos mandamientos; juicio cuya estructura es: si T ("Tatbestand") es, debe ser Z ("Zwaangsfolge"). Junto a este esquema lógico-formal que permite elaborar los conceptos "estáticos" fundamentales (como deber jurídico, pretensión, sanción, persona); KELSEN elaboró un aspecto dinámico para explicar la creación del Derecho en un orden escalonado, descendente, piramidal, que va de la constitución a la ley, de esta al reglamento, a la sentencia judicial y a la decisión administrativa, y de ahí al acto de ejecución. Pero la norma fundamental que es la cúspide de la teoría pura del derecho, no está ligada a ningún concepto ético, iusnatural, o de valor; sino que se trata de una suposición, como hipótesis del pensamiento, de que se impone la norma de que "debe obedecerse a la autoridad de la comunidad".

Bajo la inspiración de esta metodología construye MERKL su "Teoría general del Derecho Administrativo", con una consciente explicación en el prólogo de la misma. Lo que pretende elaborar un Derecho administrativo general "como abstracción a base de los parciales ordenamientos jurídico-administrativos concretos", lo mismo que "la teoría general del Estado es entendida como abstracción a base de los parciales ordenamientos jurídico-políticos concretos"; porque "la tarea propia de una disciplina especial del derecho administrativo será ofrecernos lo específico de cada uno de los derechos administrativos y lo típico de un gran número de ordenamientos jurídico-administrativo". Es consciente de la objeción ya repetida, "de que el método jurídico, que en la ocasión suele ser calificado de formalista, no es fiel a toda la rique-

\footnotetext{
58 VERDROS, "La filosofía del Derecho...", cit., págs. 286 y ss. a quien seguimos en la exposición de la teoría pura del Derecho.
} 
za de la vida. Al parecer, donde se vería más claramente la insuficiencia de semejante estilo científico es, precisamente, en la administración, una función estatal tan rica en facetas, y en la que, junto al fin de poder, asoma el fin cultural, en formas cada vez más complejas y fecundas. Pero una ciencia jurídica no tiene por qué ocuparse de los contenidos culturales; su mirada se dirige, por decirlo así, a la cáscara y no al grano. No obstante, al representar en toda su pureza las formas con que los contenidos culturales deben revestirse, sirve a éstos de manera mediata".

Destaca RECASENS SICHES la discusión mundial suscitada por la teoría pura del Derecho, y las muy abundantes críticas de que ha sido objeto; pero apunta en su haber; el valor de sus críticas sobre las doctrinas dominantes en la época prekelseniana, su influjo como vigoroso estímulo para otros pensadores jurídicos; y sus logros en varios temas centrales como la imputación jurídica, el concepto jurídico de persona, el deber jurídico y la voluntad jurídica ${ }^{59}$.

Expuestas en sus líneas generales estas tendencias metodológicas conceptualistas y formalistas, que tan decisivamente influyeron en la construcción del Derecho Administrativo como auténtica ciencia jurídica, es momento de detenerse en la crisis actual del método lógico-formal y de su positivismo de base, pues, como ha escrito GARCÍA DE ENTERRÍA, "el problema del método está hoy planteado alrededor de una cuestión básica que domina todo el panorama actual de la ciencia jurídica, la revisión del positivismo legalista que ha prevalecido durante el último siglo y medio de la ciencia jurídica" ${ }^{60}$. En síntesis las notas características atribuidas al Estado de Derecho asentado en dichas premisas son, a juicio de GARRIDO FALLA ${ }^{61}$ el formalismo (neutralismo ideológico), el positivismo ("sólo vale como Derecho aquello que expresamente se contiene en un precepto legal dictado por el órgano competente"); y la subordinación del juez con respecto al legislador ("puesto que el juez no crea el Derecho, sino que se limita aplicar el anteriormente elaborado por el legislador, su misión pierde importancia y se hace subordinada”). Estas notas, explica GARRIDO ${ }^{62}$, han sido revisadas por la reacción antiformalista, que

\footnotetext{
59 RECASENS SICHES, "Panorama del pensamiento jurídico en el siglo XX”, tomo I, págs. 187 y s., México, 1963.

60 GARCÍA DE ENTERRÍA, “Reflexiones sobre la ley...”, cit., pág. 191.

61 GARRIDO FALLA, “Dos métodos...”, págs. 21 a 60.

62 GARRIDO FALLA, "Dos métodos...”, pág.25.
} 
afirma una quiebra del positivismo por consecuencia de la pérdida de la fe en el valor de la ley escrita, la insuficiencia de la exégesis, y la existencia de un Derecho supra-legal que vendría a colocar a los Tribunales en una situación autónoma respecto de la Ley escrita. A juicio de GARRIDO no deben exagerarse estas críticas y es necesario reconocer con prudencia lo bueno que existe en el sistema en revisión y su potencialidad real para facilitar una evolución. El formalismo no ha sido tan absoluto, cuando se han consagrado los derechos naturales de los ciudadanos; es posible, pues, encontrar valores iusnaturalistas acogidos par el sistema legal que realza el positivismo, y en todo caso nuestro Derecho Administrativo, que no es obra de la jurisprudencia (como el francés), descansa sobre la ley, a la que está subordinado el juez, pero sin olvidar el espiritualismo incorporado por la Ley de la Jurisdicción contencioso-administrativa. Junto a ello, en la determinación del contenido de la norma, reconoce la influencia de un triple condicionamiento: el Derecho natural, las exigencias de la realidad y de la propia ciencia jurídica, aunque ésta tenga como tarea principal la interpretación del Derecho.

Esta posición de GARRIDO FALLA ha sido criticada, para reducirla a justas proporciones, por GARCÍA DE ENTERRÍA ${ }^{63}$ quien rechaza una rehabilitación de los dogmas positivistas, ya que, a juicio, "fueron abandonados antes por su falta de funcionamiento efectivo que por virtud de posiciones de principio”. Esta es su conclusión después de analizar las siguientes quiebras del positivismo legalista: 1) la evolución de la vida social es más rica que la tipificación de supuestos de hecho por el legislador, y esto plantea la necesidad de desvincular al Derecho como monopolio de la voluntad estatal, ya que ni siquiera la ficción de la "expansión lógica" en caso de lagunas es suficiente; 2) es prueba de ello la inadecuación de la exégesis, que se vio precisada a trasladar la indagación de la "voluntas legislatoris" a la "voluntas legis", lo que hace a la ley una expresión de algo más profundo: los principios generales, que son los únicos instrumentos disponibles para dar sentido a las instituciones y para articular estas en el sistema general del ordenamiento; 4) se ha producido una desvalorización moral y social de la ley como técnica de gobierno humano. Por todo ello concluye GARCÍA DE ENTERRÍA afirmando la jurisprudencia principal, especialmente urgida además por la contextura móvil y abierta del Derecho Administrativo, y técnicamente utilizada, para lo que le sirve de ayuda el pensamiento tópico, en la formulación de VIEHWEG, que luego analizaremos.

\footnotetext{
${ }^{63}$ GARCÍA DE ENTERRÍA, “Reflexiones sobre la ley...”, cit., págs.191 y ss.
} 
Vamos, pues, ahora a detenernos en el sociologismo y la jurisprudencia de los intereses, anotando aquí simplemente la importancia de la escuela científica francesa (GENY), en la que no nos detenemos porque, siguiendo el criterio de HERNÁNDEZ GIL ${ }^{64}$, consideramos más adecuado incluir el pensamiento de sus representantes iuspublicistas (DUGUIT, HAURIOU y JEZE) dentro del sociologismo jurídico, que al menos les sirve de ingrediente.

\section{LA JURISPRUDENCIA DE LOS INTERESES COMO PRIMADO DE LA EXPERIENCIA VITAL}

El predicamento adquirido por la jurisprudencia de los intereses está, a nuestro juicio, en desproporción con la hondura de su construcción científica; queremos decir que es un producto de fácil empirismo, revestido de una terminología poco rigurosa, hasta el punto de que continuamente $s$ han visto forzados HECK -iniciador de la teoría- y sus seguidores, a explicar el sentido del término "intereses" y la expresión "exigencia de la vida". Empero, aquel predicamento es un hecho, que LARENZ explica, en definitiva, en la práctica jurídica alemana, por el alivio que proporcionaba al juez dicha corriente metodológica, sustituyendo el método de una subsunción en los rígidos conceptos legales por el método de examen ponderador de un hecho complejo y de los intereses que entran en juego ${ }^{65}$. En definitiva, el éxito se debe a que abría un respiro en el esquema asfixiante de la jurisprudencia de conceptos; de aquí que se defina su misión como la de "aliviar la función del juez, preparando mediante la investigación de la ley u de las relaciones de la vida, la decisión adecuada".

La llamada Escuela de Tubinga, con la jefatura de HECK y las obras de RUMELIN y STAMPE, tiene su precedente en la jurisprudencia pragmática de la etapa revisionista de IHERING, y se trata de una reacción frente a la "jurisprudencia de los conceptos"66. La más explicativa obra de HECK, "Das problem der Rechtsgewinmung”- traducida con prólogo de PUIG BRUTAU ${ }^{67}$-,

${ }^{64}$ HERNÁNDEZ GIL, "Metodología...”, cit., pág. 231 del T. I.

65 LARENZ, “Metodología...”, cit., pág. 74.

66 COSSÍO, A., "Jurisprudencia conceptual y jurisprudencia de los intereses", Revista de Legislación y Jurisprudencia, 1943, págs. 463 y ss.

67 HECK, Ph., "Das problem der Rechtsgewinnung", 1912, traducción española, "El problema de la creación del Derecho", Barcelona, 1961; que seguimos en la exposición del texto, especialmente en sus págs. 68 y ss. 
sale al paso de algunas de las malas interpretaciones que se habían hecho de sus términos principales. "La característica peculiar de esta tendencia consiste en que utiliza como conceptos metódicos auxiliares el concepto de interés y la serie de nociones que están en conexión con él: estimación de intereses, situación de intereses, contenido de intereses, etc.". El término "interés" se emplea en sentido amplio; la vida plantea exigencias a la invención jurídica; dichas exigencias son posiciones reinvindicativas o de deseo. "Utilizamos, pues, -decía HECK- la palabra interés para designar cualquier disposición reivindicativa en un ámbito de cultura y sin tener en cuenta la naturaleza especial del objeto deseado: hablamos hoy no sólo de intereses materiales, sino también de intereses ideales, religiosos, nacionales, éticos. La objetiva especificidad de la jurisprudencia de intereses consiste en el esfuerzo de principio por reducir las nociones normativas que constituyen el derecho a la imbricación de esas disposiciones reivindicativas, por colmar las lagunas de la ley teniendo en consideración todas las disposiciones reivindicativas afectadas en cada caso. Este objetivo esfuerzo tiene su justificación objetiva en el hecho de que la formación del derecho está empíricamente determinada por disposiciones reivindicativas -ley y costumbre- y por el hecho de que la jurisprudencia aspira a satisfacer los deseos que se presentan en la vida"68. Especial importancia tiene la posición que al juez asigna la jurisprudencia de intereses; lo que según destacamos fue causa decisiva de su predicamento. LARENZ resume este punto con especial agudez: "La jurisprudencia de los intereses, al ordenar al juez que lleve hasta el final, respecto del caso a decidir, los juicios de valor contenidos en la ley, ha influido liberadoramente y fructíferamente -sin por ello quebrar realmente las barreras del positivismo- en una generación de juristas que había sido educada en el pensamiento formal y en el positivismo legal estricto. Tanto más cuanto que recomienda también el mismo procedimiento para completar las lagunas de la ley, abriendo así al juez la posibilidad de desenvolver el Derecho "con fidelidad a la ley" y, no obstante, de acuerdo con las necesidades de la vida" 69 .

Aparte de su valoración y crítica generales, lo que a nosotros nos interesa es inquirir sobre las posibilidades aplicativas de esta tendencia metodológica en el Derecho Administrativo. Tradicionalmente los estudiosos de lamisca han admitido su aplicación al Derecho privado, especialmente al Derecho mer-

\footnotetext{
${ }^{68}$ HECK, Ibidem, Págs. 70 y s.

${ }^{69}$ LARENZ, ob. cit., pág. 68.
} 
cantil; pero no al Derecho público, porque "sólo puede hablarse de un conflicto de intereses cuando éstos se hallen entre sí en un plano de igualdad, es decir, que sean equivalentes en el sentido de que se trate de intereses particulares de naturaleza privada o de naturaleza pública, pues no cabe un conflicto entre intereses particulares y generales, sino de subordinación de los primeros a los segundos ${ }^{70 "}$.

Entre nosotros defiende la jurisprudencia de intereses en el Derecho Administrativo GARRIDO FALLA. Es preciso, sin embargo, hacer las justas matizaciones con que ha explicado su pensamiento al respecto. Partiendo de un concepto amplio de servicio público como equivalente a interés público, GARRIDO expresó la idea de que tanto "en la construcción teórica, así como en la aplicación jurisdiccional del Derecho administrativo, se debe utilizar el método característico de una "jurisprudencia de intereses". El interés específico a tener en cuenta en estos casos sería el interés público, o sea, continuando con la terminología adoptada, el servicio público. El servicio público desempeñaría el papel de un standard de interpretación" do al paso de las críticas, reafirmó la idea invocando como argumentos de autoridad concurrentes con la prevalencia del interés administrativo, párrafos de LATOURNERIE, VITTA y BOBBIO con referencia a ORLANDO, y destacando que la crítica a la jurisprudencia de intereses en Derecho privado no tiene que aplicarse a su introducción en el Derecho Administrativo, pues en éste el interés de la Administración es prevalerte, en cuanto interés público, que engloba los intereses de cada uno de los ciudadanos que forman parte del Estado; finalmente al ser el concepto de interés público una noción contingente, se permite integrarlo en cada momento, con lo que permite que el Derecho administrativo se encuentre siempre a la altura de las circunstancias ${ }^{72}$. Esta explicación fue criticada por GONZÁLEZ PÉREZ, aún reconociendo la extraordinaria relevancia de la composición de intereses en las relaciones jurídico-administrativas; pero advierte que el interés a que aludía la Escuela de Tubinga no es el fin de la norma, o el fin del Derecho, como ocurre en el caso del Derecho Administrativo con la expresión "interés público"; sino las

${ }^{70}$ HERNÁNDEZ GIL, “Metodología...”, cit., pág. 312.

${ }^{71}$ GARRIDO FALLA, "Sobre el Derecho Administrativo y sus ideas cardinales”, R.A.P. núm. 7, pág. 45 .

72 GARRIDO FALLA, "Las transformaciones del régimen administrativo", edición 1954, págs. 81 y ss. 
apetencias o intereses que mueven al hombre a actuar; por lo que sólo la identidad de términos ("interés", "interés público") y en el común origen de las direcciones teleológicas y la jurisprudencia de intereses, puede encontrarse la explicación a la confusión de GARRIDO ${ }^{73}$. Este a reaccionado contra dicha crítica, considerando que GONZÁLEZ PÉREZ reconoce que la finalidad de las normas jurídico-administrativas es el interés público. Pero antes, GARRIDO matiza su posición, cuando, tras recoger la recta idea de FORSTHOFF de que no deben identificarse método teleológico y la jurisprudencia de intereses, dice textualmente: "Pero cuando nosotros hablamos de la jurisprudencia de intereses no estamos aceptando sin más esa postura metodológica con el valor entendido que en el Derecho privado representa; fundamentalmente la expresión no tiene aquí sino un sentido analógico"74. En tal caso, creemos, que lo que se está destacando es el elemento teleológico -interés público- en la construcción e interpretación del Derecho Administrativo, idea con la que estamos en completo acuerdo, aunque no la estimamos comprensiva de toda la respuesta necesaria a la cuestión metodológica en nuestra disciplina.

\section{E. EL SOCIOLOGISMO JURÍDICO Y LA SOCIOLOGÍA COMO DATO AUXILIAR PARA LA CONSTRUCGIÓN DEL DERECHO ADMINISTRATIVO}

$\mathrm{Al}$ igual que la jurisprudencia de intereses, el sociologismo jurídico es un intento de superación de las aporías del conceptualismo y formalismos jurídicos. En lugar de dirigirse hacia un orden superior de principios (Derecho natural), el sociologismo se centra en la realidad de los hechos sociales como auténtica infraestructura del Derecho. Para ello se nutre del método de investigación sociológica, propugnando la conversión del jurista en un sociólogo. Pero el sociologismo es algo más que la sociología del Derecho. Como expresa HERNÁNDEZ GIL ${ }^{75}$ existe entre aquél y ésta la misma diferencia que entre el historicismo jurídico y la Historia del Derecho: no se trata de estudiar el Derecho desde el punto de vista de la sociología, sino en reducir todo el hacer del jurista a la investigación sociológica del Derecho, concibiendo a este como un mero hecho social. De aquí que destaquemos en el epígrafe la separación

${ }^{73}$ GONZÁLEZ PÉREZ, "El método en el Derecho Administrativo”, R.A.P. núm. 22, págs. 68 y s.

74 GARRIDO FALLA, “Tratado...”, cit., págs. 187 a 189, especialmente notas 61 y 62 , de la $4^{\text {a }}$ ed., del vol. $1^{\circ}$.

${ }^{75}$ HERNÁNDEZ GIL, “Metodología...”, cit., pág. 266. 
entre el verdadero sociologismo y el estudio sociológico como dato auxiliar para la investigación jurídica. Sólo con este último sentido, más o menos ampliado, se encuentra la perspectiva sociológica como ingrediente de las construcciones de los iuspublicistas, especialmente de las obras de DUGUIT, HAURIOU y JEZE; por lo que, en puridad, no son sociologistas, e incluso pueden encontrarse en sus estudios las huellas de muy diversas directrices metodológicas. En el plano puro del sociologismo, señala VERDROSS que la primera exposición general de sociología jurídica se debe a MAX WEBER, con su concepto de "dominación"76. Para LARENZ los representantes de esta tendencia metodológica son EHRLICH y JERUSALEM. Consideran que la sociología jurídica es la única ciencia auténtica del Derecho, ya que no se detiene en las "palabras" ni en los conceptos huecos, sino que labora con los hechos en los que se asienta el Derecho, utilizando un método inductivo mediante la observación y recopilación de experiencias. Más que una creación metodológica lo que esos autores hacen es una crítica de la dogmática jurídica elabora en el siglo XIX ${ }^{77}$.

No se puede negar, sin embargo, el saludable efecto vivificador que produce en la ciencia jurídica esa llamada de atención sobre la realidad social. El realismo es, pues, el fruto del ingrediente sociológico incluido en la investigación, que es fácil descubrir en DUGUIT, HAURIOU y JEZE. Con cierta originalidad nos habla RECASENS SICHES de un Derecho Natural camuflado en el pensamiento de DUGUIT: admite, al menos, la existencia de unos criterios jurídicos objetivos, anteriores, exteriores y superiores al Estado, que son las normas de la solidaridad social, fundamento límite del Estado y del Derecho, y configuradora de las situaciones jurídicas subjetivas, de tal forma que distribuye las responsabilidades de todos según sus medios; y, así, la propiedad deja de ser un derecho para convertirse en una función social ${ }^{78}$.

Más armónico aparece el uso del dato sociológico en los estudios de HAURIOU, y especialmente en su creación de la teoría de la institución, que define como "una idea de obra o de empresa, que se realiza y dura jurídica-

\footnotetext{
76 VERDROS, "La filosofía del Derecho...", cit., págs. 291 y s.; la obra más significativa de WEBER, "Wirstschaf und Gesellschaft", 1922.

77 LARENZ, ob. cit., pág. 78

78 RECASENS SICHES, "Panorama del pensamiento...", cit., págs. 108 y ss.
} 
mente en un medio social; para la realización de esta idea se organiza un poder que le procura órganos; por otra parte, entre los miembros del grupo social interesado en la realización de la idea, tienen lugar manifestaciones de comunión dirigidas por los órganos del poder, y reguladas por un procedimiento"79. Admitir ese saludable efecto del dato sociológico, permite a HAURIOU incluir en la investigación jurídica las siguientes cuestiones que el normativismo abandona a la Sociología: "la individualidad objetiva del grupo, opuesta a su personalidad subjetiva; las situaciones establecidas; la adhesión al hecho; los equilibrios subjetivos; la nación, subyacente al Estado; la comunidad objetiva, subyacente a las organizaciones; y, en suma, la institución objetiva, en la cual convergen todos estos elementos" 80 . En todo caso en HAURIOU la sociología, pues, no es más que una ciencia auxiliar, y por lo mismo fructífera sin incurrir en exageraciones y pérdida del sentido jurídico.

En JEZE el realismo sociológico se hace más descarnado, por cuanto prescinde de toda valoración de justicia, para considerar los puros hechos. "A medida que avanzo en años -explicaba en el prefacio de la tercera edición francesa de sus "Principios Generales del Derecho Administrativo" 81 - más me convenzo de que lo único importante para el estudio del Derecho es un buen método. Sólo hay un método eficaz: es el de observación de los hechos". Y seguidamente hacía consideraciones sobre cuestiones de metodología de investigación y de enseñanza, afirmando, principalmente, las siguientes ideas:

a) El jurista debe observar los hechos económicos, sociales y políticos, el medio en el que nace, se desarrolla y aplica el Derecho, no como cuestión secundaria, sino como lo principal.

b) Las Facultades de Derecho deben dar primacía a la ciencia y no a la preparación profesional, porque "la educación científica es la mejor de todas las preparaciones profesionales".

c) La enseñanza de economía y ciencia política, se hace en las Facultades de Derecho yuxtaponiendo conocimientos, pero sin interpenetrarse con las disciplinas jurídicas; lo cual sería necesario para evitar caer en una enseñanza escolástica, despejada del estudio de la vida.

\footnotetext{
${ }^{79}$ HAURIOU, “La théorie de l'institution et de la fondation”, 1925.

${ }^{80}$ RECASENS SICHES, ob. cit., págs. 121 y s.

${ }^{81}$ JEZE, "Principios generales del Derecho Administrativo", Buenos Aires, 1949, págs. LIII y ss.
} 
Tradicionalmente, la cuestión del uso de la sociología en la construcción de la ciencia jurídico-administrativa, ha venido planteada como problema dentro del más general de las relaciones entre Derecho Administrativo y Ciencia de la Administración, y también en la disputa sobre la forma de construir la Parte especial de la disciplina, donde destaca la tesis radicalmente juridicista de $\mathrm{BALLBE}^{82}$. El estudio de estas implicaciones se ha realizado en otra parte de esta Memoria. Por nuestra parte estimamos de gran utilidad la sociología como dato auxiliar para la comprensión y construcción de la ciencia jurídico-administrativa.

\section{F. MODERNAS TENDENCIAS METODOLÓGICAS (REFERENCIAS AL ES- TRUCTURALISMO Y AL RENACIMIENTO DEL PENSAMIENTO TÓPICO)}

\section{a. Consideraciones generales}

Las corrientes metodológicas hasta aquí expuestas son, principalmente, de las que se han nutrido las construcciones de la ciencia jurídico-administrativa. Empero, hay que constatar el permanente afloramiento de doctrinas y teorías metodológicas generales, trasunto de las corrientes filosóficas en general y de la Filosofía del Derecho en particular. No todos los cambios de concepciones filosóficas son inmediatamente recibidos en esta parcela de la ciencia que trata del saber jurídico, del conocimiento del Derecho. Existe un lento proceso de influencia que no siempre determinará una recepción de la nueva concepción en la ciencia jurídica, bien porque se haya producido el ocaso de la teoría en el plano filosófico antes de que se consume su penetración en el plano de la concreta metodología jurídica. Con ello queremos decir que no todas las corrientes filosóficas son aplicables a la comprensión del fenómeno jurídico; ni de todas ellas deriva un a metodología con pretensiones de aplicación total. La fenomenología, el marxismo, el existencialismo, etc. señalan puntos de incidencia metodológica, bien en la mera descripción del fenómeno jurídico, o en su misma impugnación. Pero no han aportado construcciones definitivas, que puedan influir en la elaboración del Derecho Administrativo.

\footnotetext{
82 BALLBE, M., "Sistemática del Derecho Administrativo", 1947. Sobre la estructura de diversos Manuales y Tratados, Vid. recientemente. GALLEGO ANBITARTE, "Derecho Administrativo.- Programa, sistemática y guía para su estudio".- Universidad de Santiago de Compostela, 1973.
} 
Una de las notas más acusadas de nuestro tiempo es el renacimiento del Derecho natural. En el análisis del panorama del pensamiento jurídico en nuestro siglo, y en el mundo occidental, que nos ofrecen RECASENS, SICHES Y VERDROSS, en las obras que venimos citando, destaca ese aflora miento del iusnaturalismo, en unos casos como renovación de su inspiración neotomista, en otros, en la forma de axiología jurídica, o de afirmación de principios de justicia material. La prueba de los desmanes que pueden derivarse de un positivismo legalista, ofrecida por la segunda guerra mundial; aunque hay provocado posiciones de desesperanza o meramente vitalistas; ha llamado también poderosamente la atención sobre la afiliación necesaria del orden jurídico positivo a un orden superior de justicia que debe informarlos y que lo preside y trasciende.

\section{b. Referencia al estructuralismo jurídico}

Junto a esta afirmación de un orden superior de principios de justicia que preside y vivifica los ordenamientos jurídico-positivos; existen otras tendencias metodológicas que pretenden la búsqueda de la entraña misma del objeto de conocimiento procurando aprehender su estructura, a manera de esqueleto hundido en su propio cuerpo, o como la propia esencia dinámica de la realidad contemplada. En tal sentido, el estructuralismo viene ofreciendo frutos notables como metodología del conocimiento, especialmente en el campo de la Lingüística. No puede afirmarse, aún, la existencia de una prueba definitiva sobre posibles semejantes frutos de un análisis estructuralista del Derecho. Hasta el momento puede incluso dudarse de la existencia de un estructuralismo jurídico ${ }^{83}$, aunque la doctrina apunta prudentemente, en todo caso, la existencia de atisbos de ideas estructuralistas en la ciencia jurídica de los grandes maestros que han sentado las bases de las corrientes metodológicas decimonónicas. Así, HERNÁNDEZ GIL ha publicado recientemente un amplio y detenido estudio ${ }^{84}$, en el que, con gran cautela, da cuenta de algu-

83 AUZIAS, "Clefs pour le structuralisme", París, 1967 (traduc. Española, Alianza Editorial, $2^{\text {a }}$ edic., 1970). ARNAUD, "Structuralisme et droit", en "Archives de Philosophie du Droit", año 1968, t. XIII, págs. 283 y ss.; PIAGET, "Le structuralisme”, París, 1968. LEGAZ LACAMBRA, "Estructuralismo en el derecho", en Revista de la Facultad de Derecho de Madrid, t. XIII; LAMS DORFF-CALAGANE, “¿Estructuralismo en la Filosofía del Derecho?”, Santiago de Compostela, 1969.

${ }^{84}$ HERNÁNDEZ GIL, "Metodología...", tomo 2, publicado en 1971; dedica al tema los capítulos VI al XV, págs. 201 a 462; siendo el estudio más extenso y detallado que conocemos. 
nos esos atisbos en las obras de SAVIGNY -cuya noción de sistema compara con la tesis de SAUSSURE- y de IHERING -en su doctrina sobre los "cuerpos jurídicos"-; y las tesis institucionalistas de HAURIOU y SANTI ROMANO. Después de someter a crítica las obras de FROSINI, LÓPEZ CALERA, SÁNCHEZ DE LA TORRE, etc.; y de intentar delimitar la aplicación del análisis estructural al Derecho, HERNÁNDEZ GIL llega a las siguientes afirmaciones:

"1) La ciencia jurídica no puede convertirse exclusiva o plenamente en estructural, si bien es susceptible de ser analizado estructuralmente el derecho.

2) El estructuralismo jurídico contribuirá a la captación del derecho como realidad inmanente.

3) Las relaciones juridicas, el derecho y sus estructuras mantienen contactos y dependencias con las estructuras sociales, económicas y políticas. Sin embargo, el estructuralismo jurídico no ha de preocuparse tanto de las correlaciones estructurales -tema preferido de la dialéctica- cuanto de sus propias estructuras en su significado específico ${ }^{\mathrm{985}}$.

c. Peculiaridad del razonamiento jurídico: la tesis de VIEHWEG sobre el pensamiento tópico. La posición de GARCÍA DE ENTERRÍA

Hasta ahora se venía poniendo el acepto sobre la verdad y validez del contenido de las doctrinas metodológicas, es decir, de lo que sustancialmente alegaban para explicar la construcción y aplicación del Derecho; en definitiva del sistema que ofrecían para operar dentro de él, dentro de sus formulaciones axiomáticas, el proceso lógico de reducción e inducción. Pero VIEHWEG, consciente de que los esfuerzos realizados -o realizables- para la axiomatización de todo el Derecho, se han quedado hasta ahora a mitad de camino; y alentando con el hallazgo de que la forma de pensamiento antiguo que creó la jurisprudencia no era la de un pensamiento axiomático o sistemático, sino la de un pensamiento tópico; pone el acento en la necesidad de volver al estilo de la tópica tradicional, concibiendo la técnica del Derecho como expresión de la incesante búsqueda de lo justo, operando así con el problema concreto no para deducir su solución de un sistema, sino para enfrentarlo y resolverlo cada vez con la ayuda de los "topoi" o lugares comunes, de los tópicos

${ }^{85}$ HERNÁNDEZ GIL, Ibidem, pág. 462. 
que CICERÓN definió como "sedes a quipus argumenta promuntus" ${ }^{86}$. Causa verdaderamente gran impacto la sugerente presentación que hace VIEHWEG de ese clásico "ars inveniendi" que es la tópica, analizado por ARISTÓTELES, explicado por CICERÓN a un jurista amigo, recordado por VICO, utilizado por LEIBNNIZ, reflejado en el "ius civile", en el "mos italicous", y en destacados civilistas -y administrativistas, añadimos nosotros- contemporáneos.

El centro de la tópica es el problema, hacia el que orienta el pensamiento, dando pistas y señales, consejos y sugerencias, para afrontar sus aporías, o callejones sin salida. Por eso no sitúa al problema bajo un sistema dado; sino que construye el "sistema" adecuado al problema en cada caso y según sus peculiaridades, para conseguir así una concreción proporcionada, viva y actual de lo que es justo. Para VIEHWEG son tres los presupuestos:

“1. La estructura total de la jurisprudencia solamente se puede determinar desde el problema.

2. Las partes integrantes de la jurisprudencia, sus conceptos y sus proposiciones, tienen que quedar ligadas de un modo específico con el problema y sólo pueden ser comprendidas desde él.

3. Los conceptos y las proposiciones de la jurisprudencia sólo pueden ser utilizados en una implicación que conserve su vinculación con el problema. Cualquiera otra es preciso evitarla'87.

Contraponiendo VICO el cartesianismo, al que llamó método crítico, con el método tópico, destacaba las ventajas de éste. Las desventajas de aquél son "pérdida de la penetración, marchitamiento de la fantasía y de la retentiva, pobreza del lenguaje e inmadurez de juicio, en resumen, una depravación de lo humano". Frente a ello, la tópica "proporciona penetración, despierta la fantasía y la retentiva y enseña a examinar un estado de cosas desde ángulos muy diferentes $y$, por tanto, a encontrar una trama de puntos de vista”. ${ }^{88}$

${ }^{86}$ VIEHWEG, "Tópica y Jurisprudencia”, traducción española del original alemán "Topik und jurisprudenz", por DÍEZ-PICAZO, prólogo de GARCÍA DE ENTERRÍA, Madrid, 1964.- RECASENS SICHES resume íntegramente esta obra en el capítulo 65 de "Panorama del pensamiento jurídico en el siglo XX”, cit., págs. 1060 a 1080.

${ }^{87}$ VIEHWEG, Ibidem, pág. 129.

${ }^{88}$ VIEHWEG, Ibidem, pág. 27. 
En nuestra doctrina GARCÍA DE ENTERRÍA defiende la aplicación del pensamiento tópico, que viene así a dilucidar el verdadero carácter de los principios generales del Derecho, como criterios técnicos y tecnificables en los que se convierten los preceptos absolutos del Derecho natural; ya que éste no puede entenderse, a la manera que lo hacía el desacreditado iusnaturalismo racionalista del siglo VXIII, como un orden jurídico axiomático, como un primun verum del que debía de deducirse las explicaciones del Derecho positivo; sino como el orden jurídico único surgido por haber sufrido el Derecho natural "un proceso de conversión jurídica por su incorporación a las fórmulas técnicas tópicamente configuradas, que son las que se imponen la toma en consideración de un específico círculo problemático de relaciones" ${ }^{\text {89. Para }}$ GARCÍA DE ENTERRÍA son las "instituciones" -cuyo carácter primario en el pensar jurídico intuyó SAVIGNY por vez primera-, "ese lugar medio donde se realiza el encuentro de los valores superiores procedentes del Derecho natural o del orden político con los resultados del pensamiento tópico sobre los problemas singulares". "Las instituciones jurídicas -añade- se peculiarizan por una idea organizativa en servicio a la cual se especifica una técnica determinada con una interior unidad. Esa idea organizadora, que es la que ordena el sentido orgánico del conjunto, al ser a la vez una corporeización de contenidos valorativos, una pretensión de regulación social sobre un ámbito determinado de relaciones y la clase funcional de todo un mecanismo técnico en que la institución consiste, se eleva a la categoría de un verdadero principio general, que no sólo tiene un valor normativo propio, sino que además es también el que ordena y mide el alcance de los demás elementos normativos presentes en el seno de la propia institución" ${ }^{\prime \prime}$.

\section{CONCLUSIÓN}

Resulta difícil adscribirse a una única corriente metodológica, y más liberador propugnar un moderado sincretismo en el que se combinen los datos positivos que pueden extraerse de las más comprensivas de aquéllas. Procederemos primero por vía negativa, rechazando lo que no estimamos adecuado. En primer lugar no podemos aceptar el positivismo legalista, por la profunda

89 GARCÍA DE ENTERRÍA, “Reflexiones sobre la ley...”, cit., pág. 218.

${ }^{90}$ GARCÍA DE ENTERRÍA, Ibidem, pág. 220. 
convicción de su radical insuficiencia para dar un tratamiento justo y actualizado a la problemática del Derecho Administrativo. Pese a todas las cautelas, es necesario partir de la afirmación de un orden de justicia material superior a las meras formulaciones de la legislación vigente en cada momento; en esta sentido, nos sentimos partidarios del iusnaturalismo, y estimamos que el ordenamiento jurídico positivo debe estar al servicio de la justicia y de la persona humana, como explicación y justificación de todo el Derecho. Negamos, asimismo, que la función del jurista deba confundirse con la del sociólogo, con la del moralista, con la del político, con la del economista, o con la del historiador o el filósofo. Porque el Derecho está vertebrando toda la vida social, ninguno de estos aspectos de la misma pueden serle extraños, pues le interesa como presupuesto conocer los resultados de esas investigaciones: pero bien entendido, que serán meros datos a fin de poder operar en el plano de la técnica jurídica al servicio de la realización de la justicia en las reales condiciones en que se manifiesta la vida social, con todas sus encrucijadas y tensiones.

Ciertamente esa técnica jurídica requiere un peculiar arsenal de conceptos e instrumentos lógicos, y un "modus operando" propio que garantice la autenticidad y la eficacia. El método jurídico ha de ser, pues, el cauce definitivo, pero con un permanente alcance instrumental. Ante el abigarrado panorama que las numerosas normas de distinto rango ofrecen, y ante la desbordante expansión de la actividad administrativa, es imperiosamente necesario fijar puntos de referencia firmes que tanto orienten y ordenen la tarea científica, como la diaria función de los administradores y de los jueces; y esos puntos de referencia no pueden ser otros que los principios institucionales. El papel del científico difiere aquí, del aplicador del Derecho, porque si éste es el responsable de traducir en cada caso la exigencia general de dichos principios, utilizando todos los resortes que las técnicas de interpretación le ofrecen, y todas las vías que la legislación le brinda no para subrogarse en la función del legislador, sino para integrar lo que debe ser Derecho aplicable en cada caso; el científico debe llamar la atención sobre las adaptaciones, modificaciones y reformas que deben hacerse en la legislación, adelantándose a la eclosión de los problemas. Todo ello exige una vigilante actitud ante el desenvolvimiento de los hechos sociales, valorando la funcionalidad de las normas vigentes. Exige también una mayor consciencia de la potenciación del juez administrativo, prosiguiendo el camino de la especialización felizmente iniciado por nuestra ley de la Jurisdicción contencioso-administrativa; pero todavía en un insatisfactorio estado de realización.

La toma de razón del cambiante substratum social básico del Derecho Administrativo, con la necesaria valoración de los aspectos sociológicos, econó- 
micos, históricos y políticos que conlleva; el elemento teleológico básico en este Derecho, es decir las concreciones del interés público en cada momento; y los superiores postulados de justicia tecnificados como guía de las instituciones; han de ser los constantes puntos de referencia para el conocimiento, construcción y aplicación del Derecho Administrativo.

\section{EL MÉTODO DE ENSEÑANZA}

$\mathrm{Al}$ abordar el tema del método de enseñanza se produce de inmediato una conexión con la problemática general de la Universidad ${ }^{91}$ que, si bien no puede decirse que sea exclusiva de nuestro tiempo, sí ha adquirido en los últimos años unas peculiares circunstancias, que le dan un carácter insólito; entre éstas, son las más notables 1) la masificación generalizada, tanto por el extraordinario número de alumnos como por la falta en buen porcentaje de ellos de la aptitud o preparación adecuadas; 2) la tendencia a la prescripción del esfuerzo y el sacrificio para el estudio, con lo que se sitúa a la Universidad y a sus títulos en el nivel casi de artículos de consumo que pueden adquirirse en varios años de plazos, mediante el mero estar allí, y el soportar el fugaz rigor de unos exámenes parciales -cada vez urgidos en mayor número-; y 3) la desilusión de muchos profesores que se inhiben ante el cambio experimentado por la vida universitaria, o se sienten poco valorados e inmersos en una problemática que excede de la estrictamente universitaria y que tiende a condicionarles y hacerle hostil al cumplimiento de su misión. Al destacar estas características somos conscientes de que ni son las únicas, ni se ofrecen por igual en todas las Facultades, Departamentos, profesores y alumnos; pero preponderan en el conjunto. ¿Cómo cumplir, pese a ellas, la misión de la Universidad?; ¿Cómo organizar e impartir la enseñanza del Derecho Administrativo?

${ }^{91}$ Sobre el tema, POSADA, Adolfo, "Pedagogía”, Valencia, 1908; GINER DE LOS RÍOS, "Pedagogía Universitaria", Barcelona, s/f.; ORTEGA, "El libro de las misiones (Misión de la Universidad)"; GASCÓN Y MARÍN, "Cincuenta años en la Facultad de Derecho", Madrid, 1953; CALAMANDREI, P., "La Universidad de mañana", Buenos Aires, 1961, traducción de los trabajos "La facoltá de Giurisprudenza" y "La Nomina dei Professori: concorso o chiamata?", que, con otros, integraron la obra "L'Universitá di domani", Foligno, 1923; D’ORS, A., "Papeles del oficio Universitario", Madrid, 1961; ARANGUREN, J.L.L., "El futuro de la Universidad", Madrid, 1963; LATORRE, A., "Universidad y SOCIEDAD", Barcelona, 1964; AGUILAR PIÑAL, F., "Los comienzos de las crisis universitaria en España (antología de textos), Madrid, 1967, etc. etc. 


\section{A. PEDAGOGÍA, INVESTIGACIÓN Y COOPERACIÓN}

Observamos, en general, una falta de interés por la valoración y exigencia de las aptitudes pedagógicas del profesorado; y es verdaderamente imprescindible que el profesor sea capaz de transmitir la ciencia a los alumnos, mediante ese proceso comunicativo, de auténtica comunión, a través del gesto, la mirada, la palabra o el texto didácticamente presentado. En la paciencia y entusiasmo para ir facilitando esa difícil ósmosis de conocimientos, está una de las virtudes imprescindibles de un profesor, que desgraciadamente no se encuentra en todos. A partir de esa aptitud, puede el profesor realizar la necesaria aunque difícil síntesis entre teoría y práctica. La Universidad tiene una misión esencialmente científica, lo que no excluye que vele por y garantice en la medida necesaria la formación profesional. Esa medida necesaria no ésta, para nosotros, en el adiestramiento concreto del alumno para ejercer una profesión jurídica; sino en que tenga un profundo contacto experimentado con la trascendencia vital de los temas que científicamente, a la par, vienen siendo objeto de estudio. Se trata de despertar el "sentido jurídico" y borrar las barreras entre teoría y práctica.

Para ello, junto a la hábil combinación de todos los medios pedagógicos, a que luego nos referiremos, es imprescindible llevar un programa de investigación. La investigación realizada en el Departamento es el primer factor de vivificación de la enseñanza, y está llamada a mantener el rigor e interés científicos, y el compromiso serio de los estudios. En cuanto sea posible debe incorporarse de alguna manera a los alumnos a las inquietudes del programa de investigación, y procurarles una iniciación en la tarea investigadora como método de trabajo. Se conseguirá así dar un carácter dinámico a la enseñanza, convirtiendo a todos en protagonistas activos, y no en meros receptores de unos conocimientos que pueden quedar fosilizados.

Para conseguir esas metas es necesario crear y mantener un permanente sentido de cooperación. El trabajo en equipo y participado tienen que ser una preocupación común de todo el profesorado del Departamento, y tiene que extenderse al alumnado empezando primero por un testimonio de aquel; y siguiendo por una constante incitación e invitación para que el alumno no se sienta marginado, sino copartícipe activo en su propia formación. La manifestación actual, escasez de medios personales y materiales, y la atonía pueden ser serios obstáculos para conseguirlo, pero hay que tender a ello en la medida de lo posible. Más adelante nos referiremos a nuestras experiencias en el Departamento de Derecho Administrativo de la Universidad de Sevilla 


\section{B. MEDIOS Y TÉCNICAS DE ENSEÑANZA}

Entre los medios de enseñanza, nos referiremos a los personales y los materiales.

En los últimos años observamos un incesante incremento de las necesidades de profesorado, y del tiempo que éste debe dedicar al cumplimiento de su función. Puede fácilmente predecirse que el futuro ha de ser de dedicación exclusiva de todo el profesorado. Actualmente muchos profesores que se mantienen en régimen de dedicación plena, lo hacen en buena medida para no perder el contacto con la vida real del Derecho que puede proporcionarle una actividad paralela; y que es tan sumamente necesario para mantener la idoneidad precisa para desarrollar aquella dolencia con fin científico-profesional. En este sentido los Departamentos de las Facultades de Derecho están en considerable retraso con respecto, por ejemplo, de los de las Facultades de Ciencias. En éstas la relación del Departamento con la sociedad no se hace mediante actividad servicial paralela, que desvincula de la Universidad al profesorado, sino que cada vez en mayor medida, desarrollando trabajos de investigación en el propio Departamento, financiados por entidades públicas o privadas. No se desvirtúa el programa de investigación, y se garantiza una acción positiva de la Universidad en la sociedad, la cual se siente llamada a potenciar la investigación universitaria. Existen también muchas necesidades administrativas que requieren estudios especializados, que podrían ser realzados por los Departamentos de Derecho Administrativo incorporándolos a su programa de investigación, consiguiéndose así evitar la salida de la Universidad para realizar actividad paralela. Esta mayor dedicación que la Universidad actual exige al profesorado, obliga también a una interdependencia de todos los miembros del Departamento, formando un verdadero equipo. En la dirección del mismo, en la hábil distribución de tareas y en la selección de los campos a que debe extenderse el programa de investigación, juego un papel decisivo el Jefe del Departamento, pero es una responsabilidad de todos.

La relación con el alumnado es decisiva. A fin de entrar lo más eficazmente posible en el conocimiento de cada alumno, nuestra experiencia es que, además de la ficha personal, se integran en grupos de unos treinta, al frente de los cuales está un profesor. A veces nos hemos visto obligados a atribuir a un profesor más de un grupo, por la falta de colaboradores, o por estar éstos en la primera etapa de su formación, que consiste en la realización de la tesina de Licenciatura y de la tesis doctoral. Cada grupo se reúne semanalmente con su profesor en clases prácticas desde el mismo comienzo del curso, con lo cual la clase práctica cumple diversas funciones, como veremos; y, en- 
tre ellas, la de un mayor contacto y conocimiento con cada alumno. Periódicamente celebran reuniones los profesores para dar cuenta de la marcha de sus grupos y de las dificultades que se adviertan en la marcha del curso (ritmo de estudio, toma de apuntes, aclaraciones sobre puntos de la clase teórica; organización del trabajo, etc.).

Entre los medios materiales, creemos muy necesario contar con un local adecuado en el seminario para que puedan hacer uso del mismo los alumnos, y de la biblioteca, ficheros, colecciones legislativas y jurisprudencia, manuales, etc. Al frente de este servicio está un alumno de los últimos cursos, y un profesor ayudante. Es cada vez más necesario un buen servicio de redacción de apuntes; y oto de copistería, pues la experiencia no demuestra que la falta de estos medios, o incluso el distanciamiento de la bibliografía, origina lentitudes y paralizaciones, cuando no verdaderas frustraciones; porque muchas veces las dificultades materiales son más de un cincuenta por ciento de la dificultad total de la realización de los trabajos y estudios.

El fichero de alumnos y la carpeta individual clasificada son unos instrumentos imprescindibles; con ellas se cuenta con todos los datos personales, y la trayectoria seguida por el alumno; y con todos los trabajos que ha realizado durante el curso, incluidos los exámenes.

Como técnicas de enseñanza nos referiremos a las clases teóricas, clases prácticas, seminarios, dirección de lecturas y trabajos, y sesiones científicas pluridisciplinares o pluriprofesionales.

La clase teórica sigue teniendo el gran valor de ser centro de irradiación de la enseñanza básica del curso, y centro de encuentro de todo el curso con el profesorado. En la distribución de la tarea del Departamento debe fijarse con la debida antelación quien será el responsable de cada parte del programa, en los cursos de especialidad, y como se harán las suplencias. La clase teórica puede revestir dos modalidades: aquellas en la que se transmiten los conocimientos para que los alumnos tomen apuntes; y aquellas en la que previamente se han facilitado unos apuntes o textos a los alumnos, y son ellos los que, previa lectura y elaboración, suscitan las dudas, cuestiones o ampliaciones al profesor. Este, a su vez, puede suscitar la participación en aquellos puntos más relevantes que considere conveniente destacar o ampliar. En todo caso, las dos formas no son igualmente útiles; depende de cada parte del programa. Aunque hemos comprobado que siempre el apunte o el texto suele ofrecer al alumno más dificultad si no es vivificado con la eficaz exposición oral del profesor. Su facilidad expositiva, el grado de atención que pueda con- 
seguir centrar presentando con sencillas e interés los temas, son instrumentos muy necesarios para la transmisión de los conocimientos.

No deben presuponerse en los alumnos conocimientos que no tienen, pero tampoco debe disminuirse el nivel científico de los temas. El camino no puede ser otro que la sencillez expositivo, lo que exige un gran dominio de la materia y una adecuada preparación de cada clase.

Con la clase teórica se transmiten los conocimientos básicos y se coordinan la marcha del curso a través del programa. Pero necesita como primordial elemento de las clases prácticas por grupos de alumnos. Para ello es obligada una reunión previa de todos los profesores que atenderás a esos grupos, en la que se conozca la marcha de la clase teórica, y se unifique la tarea a realizar en las clases prácticas. Al comienzo del primer curso, de parte general del Derecho Administrativo, como no existe materia para iniciar los casos prácticos, la clase de dedica a aclarar dudas surgidas en las explicaciones teóricas, conseguir el manejo de las colecciones legislativas y jurisprudenciales, describir organigramas de las Administraciones territoriales, realizar lectura de artículos generales, especialmente de la Revista de Administración Pública, sobre el concepto de Administración y Derecho Administrativo, relaciones entre las funciones del Estado, etc. Cada alumno, que durante la semana anterior ha leído el trabajo indicado, actúa de ponente. Al llegar al estudio teórico de las personas jurídico-públicas y de las fuentes, ya se inician los casos prácticos, que se facilitan a los alumnos indicándoles legislación, jurisprudencia y bibliografía elemental, para que los traigan razonados por escrito en la clase siguiente. Los casos son distintos para cada grupo, aunque las materias sean comunes. A lo largo del curso cada alumno ha podido leer y exponer cuatro o cinco artículos o monografías, y habrá realizado un número aproximado de veinticinco casos prácticos de Parte General. En los Cursos se especialidad -que en la Facultad de Derecho de Sevilla son tres, en dos ramas: Derecho Público (cursos $4^{\circ}$ y $5^{\circ}$ ) y Empresa (curso $5^{\circ}$ )-, cambia el contenido de la clase práctica, porque, además de que los casos son los más reales posible y obligan a utilizar la legislación especial, y no solo las grandes leyes generales; se procura iniciar a los alumnos en la investigación, dirigiéndole los trabajos de ampliación sobre los temas que se han explicado en las clases teóricas. El alumno lee más bibliografía, y debe entregar al final del curso un trabajo cuyo tema ha elegido libremente, o dentro de la lista de temas ofrecida por el profesor.

Los Seminarios son un instrumento imprescindible para profundizar monográficamente en algunos temas. En el plan de la Facultad de Derecho de Sevilla, cada alumno de los cursos de especialidad debe elegir un seminario teó- 
rico y otro práctico. Aquellos pueden ser conjuntos, participando profesores de distintos Departamentos. Hemos intervenido con dos ponencias en su Seminario conjunto de los Departamentos de Derecho Político y Derecho Administrativo sobre "La Primacía del Poder Ejecutivo". Y hemos dirigido seminarios sobre contratación administrativa, licencias gubernativas y municipales, y el cumplimiento del principio de espiritualidad por la Jurisprudencia contencioso-administrativa española, durante quince años de vigencia de la Ley de 1956.

Las sesiones científicas suelen hacerse entre los profesores de uno o varios Departamentos, con asistencia de algunos alumnos que hacen la especialidad, y de profesionales y funcionarios (Abogados del Estado, Técnicos de Administración Civil, Secretarios de Corporaciones Locales, etc.). Se trata de exponer algún trabajo de investigación en curso, incluso los esquemas iniciales de tesis doctorales; o de estudiar conjuntamente una nueva Ley.

\section{PLAN DE ENSEÑANZA}

Como hemos indicado, en la Facultad de Derecho de Sevilla viene rigiendo un Plan especial, que distribuye la carrera en tres años comunes y dos de especialidad; a su vez, existen tres especialidades: Derecho privado, Administración Pública y Empresa. Los cursos de Derecho Administrativo son cinco: uno de Parte General, en tercer curso; dos de especialidad en la rama de Administración Pública, cursos cuarto y quinto; y uno de especialidad en la rama de Empresa, en quinto curso. El Plan de enseñanza comprende, pues, una amplia Parte General común, un curso de especialización en cuarto, donde se estudia Régimen Local, Urbanismo, y algunos servicios; un curso de Derecho Administrativo económico en quinto.

En la Parte General se combinan las técnicas de enseñanza: clases teóricas para que el alumno tome apuntes, clases teóricas participadas sobre apuntes ya facilitados al alumno, clases prácticas, controles periódicos, con realización de casos y resolución de cuestiones.

En los Cursos de especialidad se pretende conseguir tres niveles: nivel informativo (conocimiento esquemático de las cuestiones y el ordenamiento), nivel de iniciación a la investigación legislativa sobre materias concretas) y nivel de contacto con la realidad social de los temas abordados (para lo que se organizan conferencias y seminarios, con la participación de funcionarios de los servicios en estudio, directores de empresas nacionales, etc.). 
Finalmente, queremos hacer unas consideraciones sobre los exámenes. Como apuntábamos al principio existe una fuerte tendencia a la proscripción del esfuerzo y del sacrificio, y a pasar los cursos por el mero estar allí. Uno de los instrumentos que se utilizan para ello es procurar que se establezcan muchos exámenes parciales, fragmentando los programas en partes pequeñas, que pueden superarse con un mínimo esfuerzo transitorio, y luego quedan ya excluidas de examen ulterior. Creemos que si un alumno ha seguido el plan de enseñanza expuesto, para él el examen quedará reducido en gran parte, porque hemos venido constatando su preparación durante todo el curso. Pero, el alumno que no ha seguido activamente el plan de enseñanza tiene que someterse inexorablemente al examen. $\mathrm{Y}$, en todo caso, hay que evitar tantos exámenes parciales, que hacen perder la perspectiva de la asignatura, y convierten a los profesores en permanentes correctores de ejercicios, cuando sería mucho más fructífero ese esfuerzo en la dedicación a la enseñanza y a la investigación.

Pese a todas las circunstancias, debe defenderse la dignidad científica de la Universidad, y eso nos proponemos proseguir, con nuestros modestos medios y con nuestro gran entusiasmo, los que un día tuvimos la experiencia y nos propusimos servir de por vida el honor universitario, no como privilegio de dignidad, sino como gravosa tarea de servicio. 